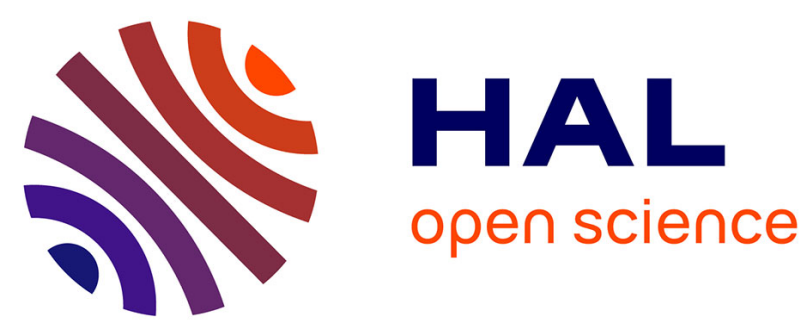

\title{
Physico-chemical properties and possible photocatalytic applications of titanate nanotubes synthesized via hydrothermal method
}

Sylwia Mozia, Ewa Borowiak-Paleń, Jacek Przepiórski, Barbara Grzmil, Tomoki Tsumura, Masahiro Toyoda, Joanna Grzechulska-Damszel, Antoni W. Morawski

\section{To cite this version:}

Sylwia Mozia, Ewa Borowiak-Paleń, Jacek Przepiórski, Barbara Grzmil, Tomoki Tsumura, et al.. Physico-chemical properties and possible photocatalytic applications of titanate nanotubes synthesized via hydrothermal method. Journal of Physics and Chemistry of Solids, 2010, 71 (3), pp.263. 10.1016/j.jpcs.2009.12.074 . hal-00615317

\section{HAL Id: hal-00615317 https://hal.science/hal-00615317}

Submitted on 19 Aug 2011

HAL is a multi-disciplinary open access archive for the deposit and dissemination of scientific research documents, whether they are published or not. The documents may come from teaching and research institutions in France or abroad, or from public or private research centers.
L'archive ouverte pluridisciplinaire HAL, est destinée au dépôt et à la diffusion de documents scientifiques de niveau recherche, publiés ou non, émanant des établissements d'enseignement et de recherche français ou étrangers, des laboratoires publics ou privés. 


\section{Author's Accepted Manuscript}

Physico-chemical properties and possible photocatalytic applications of titanate nanotubes synthesized via hydrothermal method

Sylwia Mozia, Ewa Borowiak-Paleń, Jacek Przepiórski, Barbara Grzmil, Tomoki Tsumura, Masahiro Toyoda, Joanna Grzechulska-Damszel, Antoni W. Morawski

PII: S0022-3697(09)00417-X

DOI: doi:10.1016/j.jpcs.2009.12.074

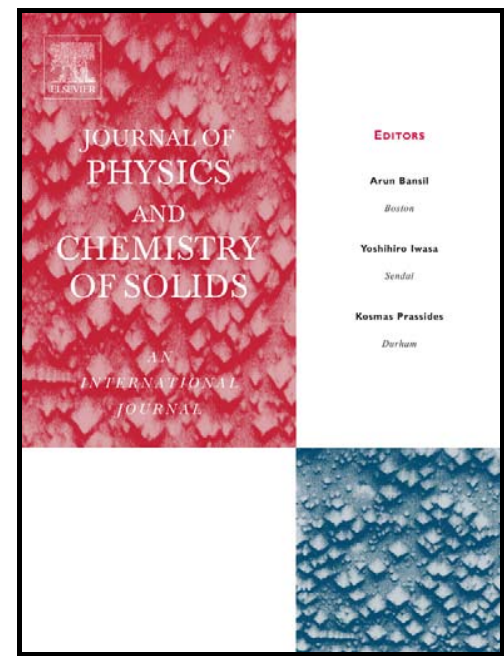

Reference: $\quad$ PCS 6063

To appear in: $\quad$ Journal of Physics and Chemistry of Solids

Received date: $\quad 16$ April 2009

Revised date: $\quad 23$ November 2009

Accepted date: 2 December 2009

Cite this article as: Sylwia Mozia, Ewa Borowiak-Paleń, Jacek Przepiórski, Barbara Grzmil, Tomoki Tsumura, Masahiro Toyoda, Joanna Grzechulska-Damszel and Antoni W. Morawski, Physico-chemical properties and possible photocatalytic applications of titanate nanotubes synthesized via hydrothermal method, Journal of Physics and Chemistry of Solids, doi:10.1016/j.jpcs.2009.12.074

This is a PDF file of an unedited manuscript that has been accepted for publication. As a service to our customers we are providing this early version of the manuscript. The manuscript will undergo copyediting, typesetting, and review of the resulting galley proof before it is published in its final citable form. Please note that during the production process errors may be discovered which could affect the content, and all legal disclaimers that apply to the journal pertain. 


\section{Physico-chemical properties and possible photocatalytic applications of titanate nanotubes synthesized via hydrothermal method}

Sylwia Mozia ${ }^{1) a)}$, Ewa Borowiak-Paleń ${ }^{1)}$, Jacek Przepiórski ${ }^{1)}$, Barbara Grzmil ${ }^{1)}$, Tomoki Tsumura $^{2)}$, Masahiro Toyoda ${ }^{2)}$, Joanna Grzechulska-Damszel ${ }^{1)}$, Antoni W. Morawski $^{1)}$

${ }^{1)}$ West Pomeranian University of Technology, Institute of Chemical and Environment Engineering, ul. Pułaskiego 10, 70 - 322 Szczecin, Poland, tel. +48 9144947 30, fax +48 91 4494686

${ }^{2}$ ) Oita University, Faculty of Engineering, Dannoharu 700, Oita 870-1192, Japan

${ }^{\text {a) }}$ corresponding author; e-mail: sylwiam@ps.pl

\section{Abstract}

Titanate nanotubes (TNTs) were prepared from $\mathrm{TiO}_{2} \mathrm{P} 25$ via hydrothermal method. The reaction temperature was 130 or $140^{\circ} \mathrm{C}$ and the reaction time was 24 or $48 \mathrm{~h}$. The samples were characterized by transmission electron microscopy, X-ray diffraction, thermogravimetry and $\mathrm{N}_{2}$ adsorption as well as Raman, FTIR-DRS and UV-Vis/DR spectroscopy. The obtained samples exhibited similar properties, regardless of the preparation temperature and time. The most notable difference between properties of TNTs prepared under different conditions was observed in case of BET surface area, which was increasing from $386 \mathrm{~m}^{2} / \mathrm{g}$ to $478 \mathrm{~m}^{2} / \mathrm{g}$ along with increasing the reaction time and temperature. Based on TEM, XRD and TG measurements we have suggested that the structure of TNTs was $\mathrm{H}_{2} \mathrm{Ti}_{2} \mathrm{O}_{4}(\mathrm{OH})_{2}$. The TEM and Raman spectroscopy measurements showed that the obtained products contained also low amount of anatase phase. The TNTs exhibited no photoactivity towards degradation of model 
azo dye Acid Red 18. However, TNTs were successfully applied for photocatalytic generation of $\mathrm{CH}_{4}$ and $\mathrm{H}_{2}$ in a solution of acetic acid. The amount of methane produced with application of TNTs synthesized at $140^{\circ} \mathrm{C}$ was about 2.5 times higher than that generated with use of $\mathrm{TiO}_{2} \mathrm{P} 25$. To the best of our knowledge this is a first report on the photocatalytic generation of hydrocarbons using TNTs in the current state of the art.

Keywords: A. nanostructures, B. chemical synthesis, C. Raman spectroscopy, D. thermogravimetric analysis (TGA)

\section{Introduction}

Since Kasuga et al. [1] described a novel hydrothermal method for titanate nanotubes (TNTs) formation, the investigations on preparation and properties of these species have attracted attention of numerous researchers. More than a decade later, the structure of TNTs as well as their properties are still a problem under discussion. Although the hydrothermal method of synthesizing of TNTs seems to be quite simple, the products obtained in different laboratories differ significantly from one to another. Due to the fact that different TNTs precursors (amorphous $\mathrm{TiO}_{2}$, anatase, rutile, mixture of both phases, such as $\mathrm{P} 25$, etc.) and reaction conditions were applied, the obtained nanotubes exhibited different surface areas, pore volumes, sodium content, etc. The main inconsistencies, however, concern crystal structure of nanotubes and their photocatalytic activity. The present debate over the crystal structure of titanate nanotubes, as summarized by Ou et al [2], is among the following: anatase $\mathrm{TiO}_{2}$, lepidocrocite $\mathrm{H}_{\mathrm{x}} \mathrm{Ti}_{2-\mathrm{x} / 4 \mathrm{x} / 4} \mathrm{O}_{4}\left(\mathrm{x} \sim 0.7\right.$, : vacancy), trititanate $\mathrm{H}_{2} \mathrm{Ti}_{3} \mathrm{O}_{7} / \mathrm{Na}_{2} \mathrm{Ti}_{3} \mathrm{O}_{7} /$ $\mathrm{Na}_{\mathrm{x}} \mathrm{H}_{2-\mathrm{x}} \mathrm{Ti}_{3} \mathrm{O}_{7}$, bititanate $\mathrm{H}_{2} \mathrm{Ti}_{2} \mathrm{O}_{4}(\mathrm{OH})_{2} / \mathrm{Na}_{2} \mathrm{Ti}_{2} \mathrm{O}_{4}(\mathrm{OH})_{2} / \mathrm{Na}_{\mathrm{x}} \mathrm{H}_{2-\mathrm{x}} \mathrm{Ti}_{2} \mathrm{O}_{5} \cdot \mathrm{H}_{2} \mathrm{O}$ or tetratitanate 
$\mathrm{H}_{2} \mathrm{Ti}_{4} \mathrm{O}_{9} \cdot \mathrm{H}_{2} \mathrm{O}$. From all the above mentioned structures, $\mathrm{Na}_{\mathrm{x}} \mathrm{H}_{2-\mathrm{x}} \mathrm{Ti}_{2} \mathrm{O}_{4}(\mathrm{OH})_{2}[3-6]$ and $\mathrm{Na}_{\mathrm{x}} \mathrm{H}_{2-}$ ${ }_{x} \mathrm{Ti}_{3} \mathrm{O}_{7}[7-9]$ seem to be the most probable. Recently, Kochkar et al. [10] presented the results of the investigations on the effect of different preparation conditions on TNTs structure. They reported that, dependent on the reaction time and temperature, as well as $\mathrm{NaOH}$ concentration, different structures, such as amorphous titania, anatase $\mathrm{TiO}_{2}$, bititanates $\left(\mathrm{H}_{2} \mathrm{Ti}_{2} \mathrm{O}_{5} \cdot \mathrm{H}_{2} \mathrm{O}\right)$ and trititanates $\left(\mathrm{Na}_{2} \mathrm{Ti}_{3} \mathrm{O}_{7}\right)$ could be obtained. Amorphous phase was also observed in case of samples treated with highly concentrated $(20 \mathrm{M}) \mathrm{NaOH}[9]$.

The photocatalytic activity of TNTs has been another unanswered question. In the "Introduction" section of numerous papers [11-15] it can be found that titanate nanotubes have potential applications in photocatalysis. However, the data on this subject which are presented in literature are rather limited and inconsistent. Yu et al [16] investigated photocatalytic oxidation of acetone in air in the presence of TNTs synthesized hydrothermally at $150^{\circ} \mathrm{C}$ for $48 \mathrm{~h}$. The authors found that prior to calcination, the nanotubes showed no photocatalytic activity. Similar observations were published by Qamar et al. in [17]. The researchers reported that the as-prepared nanotubes, with or without sodium contents, showed no photocatalytic activities towards amaranth degradation. Baiju et al. [18] presented results on the photocatalytic degradation on methylene blue (MB) on a mixed nanobelts-nanotubes titanate obtained via hydrothermal method at $150^{\circ} \mathrm{C}$ for $30 \mathrm{~h}$. The authors found that the sample exhibited very high adsorptivity towards MB. However, the photocatalytic activity was very low. Tachikawa et al. [19] investigated the photocatalytic one-electron oxidation reaction of 4-(methylthio)phenyl methanol (MTPM) in presence of titanate nanotubes, using time-resolved diffuse reflectance spectroscopy. The efficiency of the reaction was found to be rather low, although the TNTs exhibited some photocatalytic activity. On the other hand, significant activity of $\mathrm{H}$ titanate nanotubes towards synthetic dye sulforhodamine degradation under UV light was reported by Zhu et al. [20]. After $1 \mathrm{~h}$ of irradiation about $15 \%$ of the dye 
was photodegraded. Nakahira et al. [21] reported 60 to $70 \%$ photodegradation of $\mathrm{HCHO}$ in the presence of TNTs. According to Xiao et al. [22], titanate nanotubes synthesized hydrothermally at $130^{\circ} \mathrm{C}$ for $24 \mathrm{~h}$ revealed photocatalytic activity toward Rhodamine $\mathrm{B}(\mathrm{RhB})$ degradation with efficiency similar to that of P25. Photocatalytic activity of as-prepared TNTs towards methylene blue (MB) degradation and oxidation of $\mathrm{NO}$ to $\mathrm{NO}_{2}$ was reported by Inagaki et al. [23]. Similarly, Geng et al. [24] observed photodegradation of MB in the presence of TNTs. After 7 h of irradiation about $25 \%$ of MB was degraded (vs. ca. $5 \%$ during photolysis), what was accounted for the photosensitized capability of MB molecules. Recently, Costa et al. [25] reported a considerable photocatalytic activity of titanate nanotubes towards degradation of indigo carmine dye, although it was lower than that of anatase $\mathrm{TiO}_{2}$. In the presence of $\mathrm{TiO}_{2}$ the dye solution was completely decolorized during $60 \mathrm{~min}$ of the reaction, whereas the time of decolorization in the presence of the nanotubes was almost twice longer (110 $\mathrm{min})$. The authors found that a great advantage of TNTs in comparison with traditional $\mathrm{TiO}_{2}$ catalyst was that nanotubes were easily recovered from the solution. As reported by the authors, the nanotubes can be recycled and re-applied in numerous photodegradation cycles, maintaining $90 \%$ of their activity after 10 cycles of the reaction. In contrast, the precursor of $\mathrm{TiO}_{2}$ catalyst lost its activity during the second catalytic cycle [25].

Taking into consideration that in a majority of reports already published the structure of TNTs was studied on a basis of TEM and XRD measurements only, we have tried to investigate the physico-chemical properties and structure of the nanotubes in more details. The comprehensive analysis led to the estimation of the composition of TNTs, which was deduced to be $\mathrm{H}_{2} \mathrm{Ti}_{2} \mathrm{O}_{4}(\mathrm{OH})_{2}$. The structure of the TNTs was determined on a basis of TEM, $\mathrm{XRD}, \mathrm{TG}$ and $\mathrm{N}_{2}$ adsorption measurements as well as Raman, FTIR-DRS and UV-Vis/DR spectroscopy. Additionally, the photocatalytic activity of the nanotubes was investigated. The experiments concerned (i) decolorization of a model azo dye Acid Red 18 and (ii) possibility 
of photocatalytic generation of hydrocarbons (mainly methane) and hydrogen in the presence of hole scavenger such as acetic acid. To the best of our knowledge this is a first report on the photocatalytic generation of hydrocarbons using TNTs in the current state of the art. Interestingly, we have found on a basis of the experiments performed with equal catalyst loadings that the evolution of hydrocarbons was significantly higher in the presence of TNTs than in the process in which commercial P25 was applied.

\section{Experimental}

\subsection{Synthesis of TNTS}

Commercial $\mathrm{TiO}_{2} \mathrm{P} 25$ (Evonik, former Degussa, Germany) was used as a starting material for TNTs preparation. The P25 consists of $75 \%$ of anatase and $25 \%$ of rutile. The BET surface area of $\mathrm{P} 25$ is ca. $50 \mathrm{~m}^{2} / \mathrm{g}$ and the crystallite size of anatase is $25 \mathrm{~nm}$ (all data according to the manufacturer). TNT were hydrothermally synthesized as follows. $1.5 \mathrm{~g}$ of P25 was introduced to a Teflon-lined autoclave $\left(70 \mathrm{~cm}^{3}\right)$ containing $60 \mathrm{~cm}^{3} 10 \mathrm{M} \mathrm{NaOH}$. The suspension was ultrasonically treated for $1 \mathrm{~h}$ in order to allow good dispersion of $\mathrm{TiO}_{2}$ particles in the reaction mixture. After that the autoclave was heated statically at 130 or $140^{\circ} \mathrm{C}$ for 24 or $48 \mathrm{~h}$ (the samples are therefore denoted later as TNT130,24; TNT130,48; TNT140,24 and TNT140,48). After the heat treatment the $\mathrm{NaOH}$ solution was decanted and the obtained precipitate was dispersed in $0.5 \mathrm{dm}^{3}$ of $0.1 \mathrm{M} \mathrm{HCl}$. After $1 \mathrm{~h}$ the precipitate was separated from the $\mathrm{HCl}$ solution and dispersed again in $0.5 \mathrm{dm}^{3}$ of fresh $0.1 \mathrm{M} \mathrm{HCl}$. After the next $2 \mathrm{~h}$ the precipitate was washed thoroughly with deionized water (Simplicity, Millipore) until the conductivity of washing solution reached the value of $1 \mu \mathrm{S} / \mathrm{cm}$ or less. Eventually, the precipitate was dried in air at $80{ }^{\circ} \mathrm{C}$ for $24 \mathrm{~h}$. 


\subsection{Characterization of TNTs}

Transmission electron microscopy (TEM) images were recorded using FEI Tecnai F20 microscope. Samples were prepared by dispersing the powder in acetone by ultrasonic treatment, and then dropping the suspension onto a copper grid (400 mesh). X-ray diffraction (XRD) analyses were performed on a powder diffractometer Philips X'Pert PRO (CuK ${ }_{\alpha}$ $35 \mathrm{kV}, 30 \mathrm{~mA})$. Raman spectra were measured using $785 \mathrm{~nm}$ laser line $\left(\mathrm{E}_{\mathrm{laser}}=1.58 \mathrm{eV}\right)$ with a Renishaw InVia Raman microscope spectrometer. FTIR/DRS measurements were performed using Jasco FT-IR 430 (Japan) spectrometer equipped with a diffuse reflectance accessory (Harrick, USA). UV-VIS/DR spectra were recorded using Jasco V 530 spectrometer (Japan) equipped with the integrating sphere accessory for diffuse reflectance spectra. $\mathrm{BaSO}_{4}$ was used as a reference. Thermogravimetric measurements were carried out with use of STA 449C Jupiter® thermobalance (Netzsch Company, Germany). Thermal analysis was conducted under $25 \mathrm{~cm}^{3} /$ min air flow in $30-1000{ }^{\circ} \mathrm{C}$ temperature range and heating rate was $10^{\circ} \mathrm{C} / \mathrm{min}$. BET surface area was determined by $\mathrm{N}_{2}$ adsorption at $77 \mathrm{~K}$ (Autosorb 3, Quantachrome, USA).

\subsection{Photocatalytic decolorization of Acid Red 18}

The photocatalytic reaction was carried out in an open-air glass reactor containing 400 $\mathrm{cm}^{3}$ of a model solution $\left(30 \mathrm{mg} / \mathrm{dm}^{3}\right)$ of azo dye Acid Red $18\left(\mathrm{AR} 18, \mathrm{C}_{20} \mathrm{H}_{11} \mathrm{~N}_{2} \mathrm{Na}_{3} \mathrm{O}_{10} \mathrm{~S}_{3}\right.$, Chemical Factory Boruta - Kolor Sp. z o.o., Poland) and $0.3 \mathrm{~g} / \mathrm{dm}^{3}$ of P25 or TNTs. The photocatalyst loading was selected on a basis of our previous investigations on degradation of AR18 in the presence of P25 [26]. The mixture in the reactor was continuously stirred during 
the experiment. After 15 min of adsorption in the dark, the reaction mixture was illuminated with a mercury lamp emitting UV-A light (Philips Cleo, $6 \times 20 \mathrm{~W}, \lambda_{\max }=365 \mathrm{~nm}$ ). The UV lamp was positioned above the reactor. After a defined time of irradiation the samples of reaction mixture were filtered through a $0.45 \mu \mathrm{m}$ membrane filter and analyzed. The decolorization rate of AR18 was estimated on the basis of changes in UV/VIS spectra (Jasco V530 spectrometer, Japan). In order to determine the photostability of the model azo dye under the conditions applied a photolysis experiment (i.e. without addition of a photocatalyts) was performed. As found, after $5 \mathrm{~h}$ of illumination the concentration of the dye in the reaction solution remained unchanged. It means that no decomposition of the model compound took place. Therefore, it can be stated that the system was working in a pure photocatalytic regime.

\subsection{Photocatalytic generation of methane and hydrogen}

The photocatalytic reaction was conducted in a cylindrical glass reactor (Heraeus, type UV-RS-2) equipped with medium pressure mercury vapour lamp (TQ-150, $\lambda_{\max }=365 \mathrm{~nm}$ ).

The volume of the reactor was $765 \mathrm{~cm}^{3}$. In the upper part of the reactor a gas sampling port was located. At the beginning of the experiment $0.35 \mathrm{dm}^{3}$ of $\mathrm{CH}_{3} \mathrm{COOH}\left(1 \mathrm{~mol} / \mathrm{dm}^{3}\right)$ and 0.35 $\mathrm{g}$ of a catalyst were introduced into the reactor. After that $\mathrm{N}_{2}$ was bubbled through the reactor for at least $3 \mathrm{~h}$ to ensure that the dissolved oxygen was eliminated. Then, the $\mathrm{N}_{2}$ flow was stopped and UV lamp, positioned in the center of the reactor, was turned on to start the photoreaction. The mixture in the reactor was continuously stirred during the experiment. Gaseous products were analyzed using GC SRI 8610C equipped with TCD and HID detectors, and Shincarbon (carbon molecular sieve; 2m, 1mm, 100-120 mesh) and molecular sieve 5A (3m, 2mm, 80-100 mesh) columns. Helium was used as a carrier gas. 


\section{Results and discussion}

\subsection{Physico-chemical properties of titanate nanotubes}

Fig. 1 shows TEM images of TNTs prepared under different conditions. The nanotubes were scrolls with unequal number of walls on the two tube sides. The walls usually consisted of 3-4 layers. The distance between the layers, estimated from TEM measurements, was about $0.8 \mathrm{~nm}$, what is in an agreement with the literature data $[10,27,28]$. The outer diameter of the nanotubes was in the range of $7.5-11.0 \mathrm{~nm}$, whereas the inner diameter ranged from 4.5 to $6.5 \mathrm{~nm}$. No correlation between the time and temperature of the hydrothermal treatment and the diameters of TNTs could be found.

Fig. 2. presents XRD patterns of the starting material (P25) and TNTs prepared under different conditions. The diffraction pattern of $\mathrm{P} 25$ exhibits peaks of anatase and rutile. No anatase or rutile phases were detected in the XRD spectra of TNTs. Three characteristic peaks positioned at $2 \theta 24,28$ and $48^{\circ}$ in the diffraction patterns of nanotubes, have been assigned to the diffraction of titanates such as $\mathrm{A}_{2} \mathrm{Ti}_{2} \mathrm{O}_{5} \cdot \mathrm{H}_{2} \mathrm{O}, \mathrm{A}_{2} \mathrm{Ti}_{3} \mathrm{O}_{7}$, and lepidocrocite titanates [29]. Furthermore, the very weak peak at $2 \theta \sim 9.5^{\circ}$ observed in the patterns corresponds to the distance between the layers in TNTs walls.

According to Zhang et al. [5,6,30,31] the most probable structure of TNTs is $\mathrm{Na}_{2} \mathrm{Ti}_{2} \mathrm{O}_{4}(\mathrm{OH})_{2}\left(\right.$ or $\mathrm{H}_{2} \mathrm{Ti}_{2} \mathrm{O}_{4}(\mathrm{OH})_{2}$ in case of the replacement of $\mathrm{Na}^{+}$ions by $\left.\mathrm{H}^{+}\right)$. These structures can be also presented as $\mathrm{Na}_{2} \mathrm{Ti}_{2} \mathrm{O}_{5} \cdot \mathrm{H}_{2} \mathrm{O}$ and $\mathrm{H}_{2} \mathrm{Ti}_{2} \mathrm{O}_{5} \cdot \mathrm{H}_{2} \mathrm{O}$, respectively [29]. The $\mathrm{H}_{2} \mathrm{Ti}_{2} \mathrm{O}_{4}(\mathrm{OH})_{2}$ exhibits an orthorombic structure, having lattice parameters of $a=19.26$, $b=3.78$ and $c=2.99 \AA[5,6]$. Chen et al. [32] suggested that the structure of TNTs is $\mathrm{H}_{2} \mathrm{Ti}_{3} \mathrm{O}_{7}$ (monoclinic, $a=16.03, b=3.75, c=9.19 \AA$ and $\beta=101.45^{\circ}$ ). They explained that the interlayer 
spacing of $\mathrm{H}_{2} \mathrm{Ti}_{3} \mathrm{O}_{7}$ is $0.78 \mathrm{~nm}$, which is the same as that they observed in the nanotubes using SAED and HRTEM. Trititanate was also proposed as a structure of TNTs by Morgado et al. [9]. They found that the interlayer distance varied between 0.80 and $0.90 \mathrm{~nm}$, i.e. was close to the $\mathrm{d}$ values of 0.78 and $0.84 \mathrm{~nm}$ in bulk trititanates $\mathrm{H}_{2} \mathrm{Ti}_{3} \mathrm{O}_{7}$ and $\mathrm{Na}_{2} \mathrm{Ti}_{3} \mathrm{O}_{7}$, respectively. Lepidocrocite-type titanate nanotubes with general formula $\mathrm{H}_{\mathrm{x}} \mathrm{Ti}_{2-\mathrm{x} / 4 \mathrm{x} / 4} \mathrm{O}_{4}$ (orthorombic, $a=3.783, b=18.735, c=2.978 \AA$ ) was obtained by Ma et al. [33]. According to the authors the interlayer distance measured by ED was about $0.8 \mathrm{~nm}$, which was lower than the $\mathrm{d}_{020}(0.93$ $\mathrm{nm}$ ) in lepidocrocite-type titanates. The difference has been attributed to the decrease of interlayer distance as a direct consequence of the loss of hydrated water during microscopic observations carried out under high vacuum. Taking into account this phenomenon, Ma et al. [33] concluded that the lepidocrocite-type titanate is more probable structure than trititanate. They have explained that the reported interlayer distance in $\mathrm{H}_{2} \mathrm{Ti}_{3} \mathrm{O}_{7}$ of $0.78 \mathrm{~nm}$, which was calculated on a basis of TEM and electron diffraction (ED) measurements cannot be accurate and is most likely underestimated due to the loss of hydrated water under vacuum. Similar conclusions were reported by others $[10,27]$.

Taking into account that the interlayer spacing obtained from TEM measurements $(0.8$ nm, Fig. 1) is most probably underestimated, what was explained above, we suppose that the structure of the synthesized TNTs is probably $\mathrm{H}_{2} \mathrm{Ti}_{2} \mathrm{O}_{4}(\mathrm{OH})_{2}$. As was mentioned earlier, the peak at $2 \theta \sim 9.5^{\circ}$ (Fig. 2) representing the $\mathrm{d}$ spacing of the (200) planes $\left(\mathrm{d}_{200}\right)$ in $\mathrm{H}_{2} \mathrm{Ti}_{2} \mathrm{O}_{4}(\mathrm{OH})_{2}$ corresponds to the distance between adjacent layers in a multilayered nanotube (compare Fig. 1) [31]. Zhang et al. [6] reported that the intensity and position of this peak depends on the amount of inter- and intralayered -OH groups. The authors observed increased intensity of the (200) peak as a result of increasing heat treatment temperature from 100 to $500{ }^{\circ} \mathrm{C}$. Moreover, at temperatures exceeding $300^{\circ} \mathrm{C}$ the position of this peak was shifted to higher $2 \theta$ angles. Considering that the obtained TNTs contained very high amount of water 
(17-20 wt\%, see discussion on TG data), the very low intensity of the (200) peak (Fig. 2) seems to be reasonable.

The relative ratio of 110 to 600 peaks intensities can be used as a measure of sodium content. As shown in Fig. 2 the peak 600 is much less intensive than the 110 one. This suggests replacement of most of $\mathrm{Na}^{+}$ions by $\mathrm{H}^{+}$during washing with $0.1 \mathrm{M} \mathrm{HCl} \mathrm{[29].}$

As reported by Tsai et al. [29,34], samples obtained by washing at strongly acidic $\mathrm{pH}$ (1.6) were composed of anatase (major one) and protonic titanate. Washing with $\mathrm{HCl}$ at $\mathrm{pH}$ 0.38 led to formation of anatase phase only. This suggests that the transformation of protonic titanate to anatase under acidic conditions took place. The authors concluded that there was a coexistence of neighboring phases in some $\mathrm{pH}$ regimes [29]. Similarly, Lee et al. [35] found that during treatment of TNTs with $0.1 \mathrm{M} \mathrm{HCl}$ the anatase phase was formed instead of layered titanate structure. This was confirmed by XRD measurements.

In view of the above, using $0.1 \mathrm{M} \mathrm{HCl}$ in our procedure should result in the presence of anatase phase in the prepared samples (Fig. 2). However, as was mentioned earlier, neither anatase nor rutile peaks were identified in the XRD patterns of TNTs. On the other hand, careful observations of the TEM images (Fig. 1), confirm, in addition the nanotubes, presence some ball-shaped structures in the material. In view of fact that no anatase or rutile were formed, it can be deduced that these structures were amorphous $\mathrm{TiO}_{2}$. However, according to the literature $[9,10]$ presence of amorphous titania was observed in the case of treatment with highly concentrated $\mathrm{NaOH}$ and was not observed in case of $10 \mathrm{M} \mathrm{NaOH}$. The XRD analysis can not detect phases at very low concentrations. Therefore, Raman spectroscopy was used to investigate the structure the ball-shaped species. Raman spectra of P25 and titanate nanotubes prepared under different conditions are presented in Fig.3.

The spectrum of P25 exhibits modes at $143 \mathrm{~cm}^{-1}\left(\mathrm{E}_{\mathrm{g}}\right), 195 \mathrm{~cm}^{-1}\left(\mathrm{E}_{\mathrm{g}}\right), 398 \mathrm{~cm}^{-1}\left(\mathrm{~B}_{1 \mathrm{~g}}\right)$, $515 \mathrm{~cm}^{-1}\left(\mathrm{~A}_{1 \mathrm{~g}}\right)$ and $638 \mathrm{~cm}^{-1}\left(\mathrm{E}_{\mathrm{g}}\right)$, which are characteristic for anatase [36]. Moreover, rutile 
active mode at $447 \mathrm{~cm}^{-1}\left(\mathrm{E}_{\mathrm{g}}\right)$ was also detected. Compared to P25, the TNTs exhibit relative weak Raman peaks what might be attributed to a poor crystallinity. In the spectra measured for nanotubes the peak corresponding to $E_{\mathrm{g}}$ mode of anatase is shifted, compared to that in the P25 spectrum, by $5-10 \mathrm{~cm}^{-1}\left(148-158\right.$ vs. $\left.143 \mathrm{~cm}^{-1}\right)$ for TNT130,24 - TNT140,48, respectively. An occurrence of this peak demonstrates formation of the tetrahedron structure in the nanotubes [37]. According to Qian et al. [37] the blueshift might be caused by oxygen deficiency. Particularly intensive peak at $148 \mathrm{~cm}^{-1}$ observed in TNT130,24 spectra may suggest higher, compared to other samples, content of anatase. Moreover, it could be supposed that in case of TNT130,24 some amount of anatase from P25 remained unchanged and did not form the tubular structure. Thus, this peak might represent not only the newly formed anatase, but also the remains of anatase from P25. In case of the other samples the intensity of the discussed peak was significantly lower than that for TNT130,24. This suggests that presence of anatase is not associated with its residues from P25 only, but also, as was reported by Tsai et al. [29], that the transformation of protonic titanate to anatase under acidic conditions took place. Other peaks which might be related to anatase structure were found at $189 \mathrm{~cm}^{-1}$ and $390 \mathrm{~cm}^{-1}$ and were red shifted compared to the peaks measured in P25 sample. A broad and very weak peak can be observed in spectra of the TNTs samples at about $650 \mathrm{~cm}^{-}$ ${ }^{1}$. It is very difficult to assign this peak to a defined mode as one might find even two maxima in this region - one about $636 \mathrm{~cm}^{-1}$ and the second one at about $668 \mathrm{~cm}^{-1}$. The former maximum might be attributed to $\mathrm{E}_{\mathrm{g}}$ mode of anatase, whereas the latter one has been reported to be due to Ti-O-Ti [38] or Ti-O-Na [39] vibrations in nanotubes. Another peak which might be assigned to Ti-O-Na vibrations in TNT structure was identified by Bavykin et al. [38] at $917 \mathrm{~cm}^{-1}$. However, in the obtained Raman spectra (Fig. 3) this peak was not clearly detected. This could be explained by the exchange of $\mathrm{Na}^{+}$to $\mathrm{H}^{+}$during the washing step $[38,39]$. The peak at $270 \mathrm{~cm}^{-1}$ with a shoulder at $286 \mathrm{~cm}^{-1}$ can be attributed to TNT only, since it was not 
present in the P25 spectrum. This peak corresponds to Ti-O vibrating modes in titanates $[37,40]$. In Fig. 3 a well defined peak at $450 \mathrm{~cm}^{-1}$ can be also observed. This peak could be assigned to $\mathrm{E}_{\mathrm{g}}$ mode of rutile, although it is blueshifted compared to the rutile peak present in the Raman spectrum of P25 $\left(447 \mathrm{~cm}^{-1}\right)$. Moreover, the intensity of this peak in TNTs samples is higher than in case of $\mathrm{P} 25$. This might lead to a conclusion that the presence of rutile was not associated with the residues of unreacted $\mathrm{P} 25$, but rutile was formed under the conditions applied during preparation. The presence of rutile in the TNTs prepared through sonication hydrothermal combined method was reported by Ma et al. on a basis of the XRD patterns [41]. The authors supposed that the stable rutile particles did not react quickly enough with $\mathrm{NaOH}$ under conditions applied. Some authors [28] attribute the bands at $450 \mathrm{~cm}^{-1}$ to Ti-O-Ti vibrations in titanate nanotubes themselves, not in rutile. Taking into consideration that no diffraction peaks of rutile were observed in XRD patterns (Fig. 2), on the contrary to the results reported by Ma et al. [41], it could be supposed that the discussed bands are associated with TNTs. However, in order to state this unequivocally, further investigations are necessary. Summing up, study of Raman spectra of the TNTs indicate that the obtained samples were a mixture of different phases, anatase, and nanotubular titanates. The presence of rutile $\mathrm{TiO}_{2}$ is questionable, although possible.

Fig. 4 presents the FTIR/DRS spectra of P25 and TNTs obtained under different conditions. All of the presented spectra exhibit, in the $v(\mathrm{OH})$ region, one band with a maximum at $3685-3700 \mathrm{~cm}^{-1}$, which characterize the stretching vibrations of $\mathrm{Ti}^{4+}-\mathrm{OH}$ surface hydroxyl groups [42]. The broad band (from about 800 till $400 \mathrm{~cm}^{-1}$ ) was assigned to Ti-O and Ti-O-Ti skeletal frequency region [43]. The bands observed at $1630-1640 \mathrm{~cm}^{-1}$ can be assigned to molecular water bending mode [44]. In the range of $3300-3500 \mathrm{~cm}^{-1}$ the bands due to adsorbed water and hydroxyl groups can be observed in all of the spectra. Notably, the content of water adsorbed in the titanate nanotubes was significantly higher than 
in P25, owing to the increase of the specific surface areas and pore volumes (compare Table 1).

High water content in the prepared samples was confirmed on a basis of TG measurements. Fig. 5a shows TG curves measured for TNTs prepared under different conditions. It can be clearly seen that more significant weight loss $(\Delta W)$ took place in case of the TNTs prepared at $130^{\circ} \mathrm{C}$ than in case of those prepared at $140^{\circ} \mathrm{C}$. The total (i.e. in the range of $24-1000^{\circ} \mathrm{C}$ ) weight loss amounted to ca. $20 \mathrm{wt} \%$ and ca. $17 \mathrm{wt} \%$ for TNTs prepared at 130 and $140^{\circ} \mathrm{C}$, respectively. It was found that the highest difference in the $\Delta W$ for TNTs prepared at different temperatures was observed below $100^{\circ} \mathrm{C}$. The $\Delta W$ between room temperature and $100^{\circ} \mathrm{C}$ was about $8 \mathrm{wt} \%$ and $5.5 \mathrm{wt} \%$ for samples prepared at 130 and $140^{\circ} \mathrm{C}$, respectively. Taking into consideration that the samples were synthesized during different periods of time, the observed differences might have been due to the adsorption of water on prepared materials during their storage and handling. Moreover, since this weight loss was associated with the release of water physically adsorbed on the samples and cannot be used as a measure of TNTs structure, there is no need to look more deeply into these results. In case of higher temperatures the results obtained for TNTs prepared at $130^{\circ} \mathrm{C}$ and $140^{\circ} \mathrm{C}$ were similar one to another. The $\Delta W$ in the range of $100-200{ }^{\circ} \mathrm{C}$ was ca. $8.0-8.5 \mathrm{wt} \%$ and in the range of $200-500^{\circ} \mathrm{C}$ ca. $3.5 \mathrm{wt} \%$, regardless of the sample preparation conditions. The weight loss at the temperatures above $100^{\circ} \mathrm{C}$ is attributed to the dehydration of interlayered and intralayered -OH groups [45]. No weight loss was observed at temperatures above $500^{\circ} \mathrm{C}$.

Fig. 5b shows, as an example, DTG curve obtained for TNTs synthesized hydrothermally at $130^{\circ} \mathrm{C}$ for $24 \mathrm{~h}$. The DTG curves calculated for the other samples exhibited similar shape. The broad distinct peak with a minimum at $89^{\circ} \mathrm{C}$ represents the release of water physically adsorbed on the samples. The considerable weight loss suggests also high adsorption capacity of TNTs towards water, including moisture contained in air, which is 
associated with high BET surface area (Table 1). From Fig. 5b it can be also found that on the right edge of the discussed peak a weak shoulder at about $140^{\circ} \mathrm{C}$ is present. This shoulder could be related to the desorption of moisture or it might suggest that at this temperature desorption of chemisorbed water started.

Some authors $[8,9,46]$ have tried to calculate the formula of the TNTs from the TG measurements. Thorne et al. [46] argued on the basis of the weight loss between 100 and $500^{\circ} \mathrm{C}$ that the stoichiometry of the TNTs was $\mathrm{H}_{0.67} \mathrm{TiO}_{2.33} \cdot 0.28 \mathrm{H}_{2} \mathrm{O}_{\text {abs }}$ or $\mathrm{H}_{2} \mathrm{Ti}_{3} \mathrm{O}_{7} \cdot 0.8 \mathrm{H}_{2} \mathrm{O}_{\text {abs }}$. The same phase composition of TNTs was proposed by Morgado et al. $[8,9]$. The 7-9\% weight loss at temperatures from 100 to $500^{\circ} \mathrm{C}$ observed by the authors was attributed to the thermal decomposition of $\mathrm{H}_{2} \mathrm{Ti}_{3} \mathrm{O}_{7}$ according to the following reaction: $\mathrm{H}_{2} \mathrm{Ti}_{3} \mathrm{O}_{7} \rightarrow 3 \mathrm{TiO}_{2}+$ $\mathrm{H}_{2} \mathrm{O}$.

In case of our samples such a calculation is rather difficult to be performed because the obtained materials were not pure TNTs. As was mentioned earlier, we have supposed that the samples contained some amount of anatase. Since exact content of this "impurity" can not be estimated, calculation of the chemical formula for the TNTs seems to be not possible. However, because no diffraction peaks related to this phase of $\mathrm{TiO}_{2}$ were observed in the $\mathrm{XRD}$ patterns, an assumption that anatase content in the prepared materials is low, seems to be reasonable. Therefore we tried to estimate a proximate formula of TNTs from TG results. As we have discussed earlier, on a basis of the XRD measurement of TNTs (Fig. 2) we concluded that the samples contain $\mathrm{H}_{2} \mathrm{Ti}_{2} \mathrm{O}_{4}(\mathrm{OH})_{2}$. Taking into account results presented by Zhang et al. [6] we might assume that the dehydration reaction of $\mathrm{H}_{2} \mathrm{Ti}_{2} \mathrm{O}_{4}(\mathrm{OH})_{2}$ consists of two steps which can be illustrated by the following reactions:

$$
\begin{aligned}
& \mathrm{H}_{2} \mathrm{Ti}_{2} \mathrm{O}_{4}(\mathrm{OH})_{2} \rightarrow \mathrm{H}_{2} \mathrm{O}+\mathrm{H}_{2} \mathrm{Ti}_{2} \mathrm{O}_{5} \\
& \mathrm{H}_{2} \mathrm{Ti}_{2} \mathrm{O}_{5} \rightarrow \mathrm{H}_{2} \mathrm{O}+2 \mathrm{TiO}_{2} \text { (anatase) }
\end{aligned}
$$


The reaction (1) might be attributed to the weight loss below $100^{\circ} \mathrm{C}$, whereas the reaction (2) might be associated with $\Delta W$ in the range of $100-500{ }^{\circ} \mathrm{C}$. The calculated theoretical weight loss due to the reaction (2) equals to ca. $10 \mathrm{wt} \%$. This value is lower than the one measured thermogravimetrically (i.e. $11.5-12 \mathrm{wt} \%$ ). The $11.5-12 \mathrm{wt} \%$ weight loss is, however, closer to the structural water loss of $10 \mathrm{wt} \%$ due to the thermal decomposition of $\mathrm{H}_{2} \mathrm{Ti}_{2} \mathrm{O}_{5}$, than to the $7 \mathrm{wt} \%$ due to the decomposition of $\mathrm{H}_{2} \mathrm{Ti}_{3} \mathrm{O}_{7}$. Therefore, the structure of $\mathrm{H}_{2} \mathrm{Ti}_{2} \mathrm{O}_{4}(\mathrm{OH})_{2}$ seems to be more probable than the $\mathrm{H}_{2} \mathrm{Ti}_{3} \mathrm{O}_{7}$.

On the other hand, if we go back to the DTG curve and take into consideration the weak shoulder at about $140^{\circ} \mathrm{C}$, we might assume that the weight loss due to the release of physisorbed water did not complete below $100^{\circ} \mathrm{C}$, but it proceeded up to $140^{\circ} \mathrm{C}$. Thus, the weight loss which is attributed to the dehydration of interlayered and intralayered $\mathrm{OH}$ groups might be calculated for the temperatures range of $140-500^{\circ} \mathrm{C}$. The $\Delta W$ calculated in this temperature range was about 7.1-7.3\%, being the highest for TNT130,24. This value might suggest that the structure of TNTs was not $\mathrm{H}_{2} \mathrm{Ti}_{2} \mathrm{O}_{4}(\mathrm{OH})_{2}$, but $\mathrm{H}_{2} \mathrm{Ti}_{3} \mathrm{O}_{7}$. This way of calculations, however, seems to be rather doubtful. An additional peak in DTG curve at about $135^{\circ} \mathrm{C}$, can be attributed to the release of interlayer water, as was reported by Morgado et al. [8]. If the shoulder observed at about $140^{\circ} \mathrm{C}$ corresponds to the interlayer water, the calculation mentioned above should not be performed within the $140-500^{\circ} \mathrm{C}$ range, but for temperatures from 100 to $500^{\circ} \mathrm{C}$, what was discussed earlier. In view of this, again, the $\mathrm{H}_{2} \mathrm{Ti}_{2} \mathrm{O}_{4}(\mathrm{OH})_{2}$ seems to be more probable structure than the $\mathrm{H}_{2} \mathrm{Ti}_{3} \mathrm{O}_{7}$.

The obtained data might lead to a conclusion that estimation of TNTs structure on a basis of thermogravimetric measurements cannot give reliable results because the TG and DTG curves obtained for TNTs could be interpreted in several ways. However, it must be stressed here once again that all of the presented calculations were approximates only because the samples contained some amount of anatase, what was found from the Raman spectra. The 
presence of anatase should affect the value of $\Delta W$. It could be supposed that in case of the sample without this "impurity" the weight loss should be even higher than the observed one.

Fig. 6 presents the $\mathrm{N}_{2}$ adsorption - desorption isotherms of titanate nanotubes prepared under different conditions. All samples showed the type IV isotherms with type H3 hysteresis loops according to IUPAC [47] classification. The initial part of the Type IV isotherm is attributed to monolayer-multilayer adsorption. Hysteresis appearing in the multilayer range of physisorption isotherms is usually associated with capillary condensation in mesopore structures. The Type H3 loop is observed with aggregates of plate-like particles giving rise to slit-shaped pores [47]. Taking into consideration that titanate nanotubes are multiwalled scrolls which are believed to be formed through sheet folding or wrapping mechanism $[9,15]$ it seems to be reasonable that they exhibit the H3 loop. The surface properties of TNTs determined on a basis of $\mathrm{N}_{2}$ adsorption - desorption measurements are presented in Table 1. It can be observed that the BET specific surface area increased along with hydrothermal reaction time and temperature. The lowest BET surface area was observed for sample prepared at $130^{\circ} \mathrm{C}$ for $24 \mathrm{~h}\left(386 \mathrm{~m}^{2} / \mathrm{g}\right)$, whereas the highest surface area was measured in case of TNT140,48 $\left(478 \mathrm{~m}^{2} / \mathrm{g}\right)$. Similarly, the total pore volume was increasing from 1.31 to 1.69 $\mathrm{cm}^{3} / \mathrm{g}$ for TNT130,24 - TNT140,48, respectively. The obtained values are consistent with the literature data $[48,49]$. For example, Tsai et al. [48] reported that the BET surface area of TNTs prepared via hydrothermal method at $130^{\circ} \mathrm{C}$ for $24 \mathrm{~h}$ was equal to $399 \mathrm{~m}^{2} / \mathrm{g}$ and the pore volume was $1.47 \mathrm{~cm}^{3} / \mathrm{g}$. Wang et al. [49] prepared titanate nanotubes at $130^{\circ} \mathrm{C}$ for $20 \mathrm{~h}$. The BET surface area of such prepared samples was equal to $375 \mathrm{~m}^{2} / \mathrm{g}$.

On a basis of $\mathrm{N}_{2}$ adsorption data the average pore diameter was also calculated (Table 1). The values of this parameter were similar for all the samples and ranged from 13.6-14.2 nm. Taking into consideration that the average inner diameter of TNTs determined from TEM measurements was in the range of 4.5-6.5 $\mathrm{nm}$ it is clear that the method of nitrogen adsorption 
overestimates the average diameter of nanotubes. According to Bavykin et al. [15] the method accounts for the pores not only inside the tubes but also for the pores between the tubes. These external pores are usually bigger than the internal pores and the size of these pores depends on the way the nanotubes have been agglomerated into the bundles.

Fig. 7 presents UV-Vis diffuse reflectance spectra of titanate nanotubes prepared at different temperatures and for different heating times. For comparison, the spectrum of P25 $\mathrm{TiO}_{2}$ is also shown. The TNTs spectra, regardless of the samples preparation conditions, exhibit a similar course and are blue shifted for about $20 \mathrm{~nm}$ relative to $\mathrm{P} 25$. This indicates the increase of the band gap energy. Wang et al. [49] attributed the shift to hydration and nanosize effect of TNTs. To determine the band gap energy $\left(E_{g}\right)$ of the samples, the KubelkaMunk method was used. The $E_{g}$ values were calculated from the $(F(R) h v)^{1 / 2}$ versus $h v$ plots, where $F(R)=(1-R) / 2 R[50]$. The absorption edges were found to be $378 \mathrm{~nm}$, which value corresponds to the band gap energy of $\mathrm{E}_{\mathrm{g}}=3.28 \mathrm{eV}$. The absorption edge and $\mathrm{E}_{\mathrm{g}}$ determined for P25 were $399 \mathrm{~nm}$ and $3.10 \mathrm{eV}$, respectively. This value is consistent with the already published results [50]. The literature data $[49,51,52]$ concerning band gap of titanate nanotubes are inconsistent. Some researchers found that $\mathrm{E}_{\mathrm{g}}$ of TNT was higher than that of anatase, whereas others reported inverse relation. For example, Yu et al. [51] reported that $\mathrm{E}_{\mathrm{g}}$ of TNTs prepared from rutile ranged from 3.03 to $3.15 \mathrm{eV}$, depending on the hydrothermal treatment time. Such low values of $\mathrm{E}_{\mathrm{g}}$ were associated with a high rutile content in the prepared samples. Khan et al. [52] found the band gap of $3.1 \mathrm{eV}$, whereas Wang et al. [49] determined the $\mathrm{E}_{\mathrm{g}}=3.6 \mathrm{eV}$. Bavykin et al. $[15,53]$ reported $\mathrm{E}_{\mathrm{g}}$ value as high as $3.87 \mathrm{eV}$. The results obtained during our investigations (Fig. 7) show that $E_{g}$ of TNTs was higher than that of pure anatase (3.23 eV, data not shown), although the difference was negligible.

Summing up, it may be stated that the preparation conditions in the range of the investigations (i.e. temperature of $130-140^{\circ} \mathrm{C}$ and time of $24-48 \mathrm{~h}$ ) have no significant effect 
on the the physico-chemical properties of TNTs. Nevertheless, notable increase in BET surface area could be found for samples prepared at higher temperatures and during longer periods of time. Minor differences in TNTs structure were confirmed by the Raman spectra. The XRD, TG, FT-IR and UV-Vis/DR measurements suggest that all the samples exhibited similar properties.

\subsection{Photocatalytic behaviour of titanate nanotubes. Decolorization of Acid Red 18}

Fig. 8 illustrates changes of AR18 concentration during photocatalytic reaction conducted in the presence of titanate nanotubes and P25. For clarity, the results obtained with TNT130,24 only are presented. The results obtained with TNTs prepared at $130^{\circ} \mathrm{C}$ for $48 \mathrm{~h}$ and at $140{ }^{\circ} \mathrm{C}$ were similar. During $5 \mathrm{~h}$ of irradiation the concentration of AR 18 remained practically constant. This indicates that titanate nanotubes exhibited no photoactivity. On the other hand, when P25 was applied as a photocatalyst the reaction solution was completely decolorized after $3 \mathrm{~h}$ of the process. The obtained results are consistent with the photocatalytic behavior of TNTs observed by Yu et al. [16] and Qamar et al. [17]. The lack of photoactivity of TNTs clearly shows that titanates such as $\mathrm{H}_{2} \mathrm{Ti}_{2} \mathrm{O}_{4}(\mathrm{OH})_{2}$ are not active under UV light. The observed decrease of AR18 concentration for ca. $0.6 \%$ during $5 \mathrm{~h}$ of irradiation might be associated with accuracy of the measurement or attributed to low content of highly photoactive anatase in the TNTs sample, what was discussed earlier.

On the basis of the photocatalytic experiments it can be concluded that unmodified, asreceived TNTs have no potential application in photocatalytic removal of organic compounds, such as azo dyes, from water. 


\subsection{Photocatalytic behaviour of titanate nanotubes. Generation of hydrocarbons and hydrogen}

To our best knowledge, no investigations on methane formation in the presence of TNTs and sacrificial agents have been reported up till now. The literature data concerning photocatalytic generation of methane from organic compounds in liquid phase are very limited. All of them concern production of $\mathrm{CH}_{4}$ from aliphatic acids [54-57] and alcohols [58]. In 1970's Kraeutler and Bard [54-56] published a series of papers concerning photocatalytic decarboxylation of acetic acid in the presence of $\mathrm{Pt} / \mathrm{TiO}_{2}$ catalyst. Similarly, Sakata et al. [57] observed formation of methane and ethane during photodecomposition of acetic and propionic acids in the presence of $\mathrm{TiO}_{2}$ and $\mathrm{Pt} / \mathrm{TiO}_{2}$. We expect that development of photocatalytic generation of methane might be an interesting alternative for the conventional technology of biogas production based on anaerobic digestion. Aliphatic acids, which are the hole scavengers, are by-products of photocatalytic degradation of most organic compounds in water. This suggests that different wastewaters might be potential sources of methane. Therefore, we have tried to investigate the possibility of methane generation with application of TNTs. Acetic acid was used as a model compound.

Fig. 9 presents a comparison of the amounts of different gaseous products evolved during irradiation of $\mathrm{CH}_{3} \mathrm{COOH}$ solution in the presence of titanate nanotubes or $\mathrm{P} 25$. The hydrocarbon generated at the highest concentration was, regardless of the photocatalyst used, methane. It is evident that the amount of $\mathrm{CH}_{4}$ obtained during the reaction conducted with TNTs was significantly higher than in case of P25. After $5 \mathrm{~h}$ of the process the concentration of $\mathrm{CH}_{4}$ in gaseous mixture was ca. 1.3, 1.6 and $0.6 \% \mathrm{v} / \mathrm{v}$ for TNT130,24; TNT140,48 and P25, respectively. Other hydrocarbons identified were ethane and propane. The concentration of $\mathrm{C}_{2} \mathrm{H}_{6}$ was in the range of $0.09-0.13 \% \mathrm{v} / \mathrm{v}$, and $\mathrm{C}_{3} \mathrm{H}_{8}$ in the range of $0.003-0.007 \% \mathrm{v} / \mathrm{v}$, 
being the lowest for P25. Except from aliphatic hydrocarbons, hydrogen was also detected. The highest concentration of $\mathrm{H}_{2}$ was observed in case of TNT130,24 $(0.13 \% \mathrm{v} / \mathrm{v})$.

Surprisingly, TNT140,48, being the most efficient in generation of hydrocarbons, was the least effective in hydrogen production from all the samples used. The highest activity of TNT140,48 in generation of aliphatic hydrocarbons might be attributed to the high BET surface area of this sample. The surface area is often reported to be an important factor affecting the photocatalytic activity of different catalyst. The mechanism of methane formation is based on the reaction of acetic acid with photogenerated holes leading to decarboxylation of $\mathrm{CH}_{3} \mathrm{COOH}$ [54-57]. High surface area allows better contact between acetic acid molecules and TNTs surface what might be responsible for better activity of TNT140,48 than TNT130,24.

The obtained data show that TNTs might be successfully applied for photocatalytic generation of methane and hydrogen in the presence of sacrificial agents, such as acetic acid. Most of the literature data [54-57] concerning photocatalytic methane generation, report application of photocatalysts containing $\mathrm{Pt}$, which is an expensive material. Therefore, further investigations on application of TNTs in this process seem to be reasonable.

\section{Conclusions}

The effect of the temperature and time of hydrothermal treatment on physico-chemical properties of TNTs was investigated. It was found that the obtained nanotubes exhibited similar properties, regardless of the reaction temperature $\left(130\right.$ or $\left.140{ }^{\circ} \mathrm{C}\right)$ and time $(24$ or $48 \mathrm{~h})$. The most notable difference between properties of TNTs prepared under different conditions was observed in case of BET surface area, which was increasing with increasing the reaction time and temperature. Based on TEM, XRD and TG measurements we suggest that the crystal structure of TNTs was $\mathrm{H}_{2} \mathrm{Ti}_{2} \mathrm{O}_{4}(\mathrm{OH})_{2}$. The TEM and Raman spectroscopy measurements 
showed that the obtained product was not pure TNTs, but contained small amounts of anatase phase. The TNTs exhibited no photoactivity towards degradation of model azo dye AR18. Thus, it can be concluded that that unmodified, as-received TNTs have no potential application in photocatalytic removal of organic compounds, such as azo dyes, from water. However, TNTs might be successfully applied for photocatalytic generation of methane and hydrogen in the presence of sacrificial agents, such as acetic acid. The amount of methane produced in the presence of TNTs 140,48 was about 2.5 times higher than in case of $\mathrm{TiO}_{2} \mathrm{P} 25$. Further investigations on the generation of methane and hydrogen in the presence of TNTs are in progress.

\section{Acknowledgements}

The presented research is co-financed by the Foundation for Polish Science, which has been supported by a grant from Iceland, Liechtenstein and Norway through the EEA Financial Mechanism.

The research has been performed within a frame-work of Polish-Japanese scientific and technological international cooperation joint project for the years 2009-2010. 


\section{References}

[1] T. Kasuga, M. Hiramatsu, A. Hoson, T. Sekino, K. Niihara, Formation of Titanium Oxide Nanotube, Langmuir 14 (1998) 3160-3163.

[2] H. H. Ou, S.-L. Lo, Review of titania nanotubes synthesized via the hydrothermal treatment: Fabrication, modification, and application, Sep. Purif. Technol. 58 (2007) 179-191. [3] J.-N. Nian, H. Teng, Hydrothermal synthesis of single-crystalline anatase $\mathrm{TiO}_{2}$ nanorods with nanotubes as the precursor, J. Phys. Chem. B 110 (2006) 4193-4198.

[4] L. Zhang, H. Lin, N. Wang, Ch. Lin, J. Li, The evolution of morphology and crystal form of titanate nanotubes under calcination and its mechanism, J. Alloy. Compd. 431 (2007) 230235. 
[5] J. Yang, Z. Jin, X. Wang, W. Li, J. Zhang, S. Zhang, X. Guo, Z. Zhang, Study on composition, structure and formation process of nanotube $\mathrm{Na}_{2} \mathrm{Ti}_{2} \mathrm{O}_{4}(\mathrm{OH})_{2}$, Dalton Trans., 20 (2003) 3898-3901.

[6] M. Zhang, J. Zhensheng, J. Zhang, X. Guo, J. Yang, W. Li, X. Wang, Z. Zhang, Effect of annealing temperature on morphology, structure and photocatalytic behavior of nanotubed $\mathrm{H}_{2} \mathrm{Ti}_{2} \mathrm{O}_{4}(\mathrm{OH})_{2}$, J. Mol. Catal. A: Chemical 217 (2004) 203-210.

[7] E. Morgado Jr., M.A.S. de Abreu, G.T. Moure, B.A. Marinkovic, P.M. Jardim, A.S. Araujo, Effects of thermal treatment of nanostructured trititanates on their crystallographic and textural properties, Mater. Res. Bulletin 42 (2007) 1748-1760.

[8] E. Morgado Jr., M. A. S. de Abreu, O. R. C. Pravia, B. A. Marinkovic, P. M. Jardim, F. C. Rizzo, A. S. Araújo, A study on the structure and thermal stability of titanate nanotubes as a function of sodium content, Solid State Sci. 8 (2006) 888-900.

[9] E. Morgado, Jr., M. A. S. de Abreu, G. T. Moure, B. A. Marinkovic, P. M. Jardim, A. S. Araujo, Characterization of nanostructured titanates obtained by alkali treatment of $\mathrm{TiO}_{2}$ anatases with distinct crystal sizes, Chem. Mater. 19 (2007) 665-676.

[10] H. Kochkar, N. Lakhdhar, G. Berhault, M. Bausach, A. Ghorbel, Optimization of the alkaline hydrothermal route to titanate nanotubes by a Doehlert matrix experience design, J. Phys. Chem. C 113 (2009) 1672-1679.

[11] L.-D. Gao, Y. Le, J.-X. Wang, J.-F. Chen, Preparation and characterization of titania nanotubes with mesostructured walls, Mater. Lett. 60 (2006) 3882-3886.

[12] M. Miyauchi, H. Tokudome, Low-reflective and super-hydrophilic properties of titanate or titania nanotube thin films via layer-by-layer assembly, Thin Solid Films 515 (2006) 20912096.

[13] T. Kasuga, Formation of titanium oxide nanotubes using chemical treatments and their characteristic properties, Thin Solid Films 496 (2006) 141-145. 
[14] T. Kubo, A. Nakahira, Local structure of $\mathrm{TiO}_{2}$-derived nanotubes prepared by the hydrothermal process, J. Phys. Chem. C 112 (2008) 1658-1662.

[15] D.V. Bavykin, J.M. Friedrich, F.C. Walsh, Protonated titanates and $\mathrm{TiO}_{2}$ nanostructured materials: synthesis, properties and applications, Adv. Mater. 18 (2006) 2807-2824.

[16] J. Yu, H. Yu, B. Cheng, C. Trapalis, Effects of calcination temperature on the microstructures and photocatalytic activity of titanate nanotubes, J. Mol. Catal. A: Chemical 249 (2006) 135-142.

[17] M. Qamar, C.R. Yoon, H.J. Oh, N.H. Lee, K. Park, D.H. Kim, K.S. Lee, W.J. Lee, S.J. Kim, Preparation and photocatalytic activity of nanotubes obtained from titanium dioxide, Catal. Today 131 (2008) 3-14.

[18] K.V. Baiju, S. Shukla, S. Biju, M.L.P. Reddy, K.G.K. Warrier, Hydrothermal processing of dye-adsorbing one-dimensional hydrogen titanate, Mater. Lett. 63 (2009) 923-926. [19] T. Tachikawa, S. Tojo, M. Fujitsuka, T. Sekino, T. Majima, Photoinduced charge separation in titania nanotubes, J. Phys. Chem. B, 110 (2006) 14055-14059.

[20] H. Zhu, X. Gao, Y. Lan, D. Song, Y. Xi, J. Zhao, Hydrogen titanate nanofibers covered with anatase nanocrystals: A delicate structure achieved by the wet chemistry reaction of the titanate nanofibers, J. Am. Chem. Soc., 126 (2004) 8380-8381.

[21] A. Nakahira, W. Kato, M. Tamai, T. Isshiki, K. Nishio, Synthesis of nanotube from a layered $\mathrm{H}_{2} \mathrm{Ti}_{4} \mathrm{O}_{9} \cdot \mathrm{H}_{2} \mathrm{O}$ in a hydrothermal treatment using various titania sources, J. Mater. Sci. 39 (2004) 4239-4245.

[22] M. W. Xiao, L.S. Wang, X. J. Huang, Y. D. Wu, Z. Dang, Synthesis and characterization of $\mathrm{WO}_{3} /$ titanate nanotubes nanocomposite with enhanced photocatalytic properties, J. Alloy. Compd. 470 (2009) 486-491. 
[23] M. Inagaki, N. Kondo, R. Nonaka, E. Ito, M. Toyoda, K. Sogabe, T. Tsumura, Structure and photoactivity of titania derived from nanotubes and nanofibers, J. Hazard. Mater. 161 (2009) 1514-1521.

[24] J. Geng, D. Yang, J. Zhu, D. Chen, Z. Jiang, Nitrogen-doped $\mathrm{TiO}_{2}$ nanotubes with enhanced photocatalytic activity synthesized by a facile wet chemistry method, Mater. Res. Bulletin 44 (2009) 146-150.

[25] L. L. Costa, A. G.S. Prado, $\mathrm{TiO}_{2}$ nanotubes as recyclable catalyst for efficient photocatalytic degradation of indigo carmine dye, J. Photochem. Photobio. A: Chemistry 201 (2009) 45-49.

[26] S. Mozia, M. Tomaszewska, A. W. Morawski, Photocatalytic degradation of azo-dye Acid Red 18, Desalination 185 (2005) 449-456.

[27] R. Ma, Y. Bando, T. Sasaki, Directly rolling nanosheets into nanotubes, J. Phys. Chem. B 108 (2004) 2115-2119.

[28] J. A. Toledo-Antonio, S. Capula, M. Antonia Cortés-Jácome, C. Angeles-Chávez, E. López-Salinas, G. Ferrat, J. Navarrete, and J. Escobar, Low-temperature FTIR study of CO adsorption on titania nanotubes, J. Phys. Chem. C 111 (2007) 10799-10805.

[29] Ch.-Ch. Tsai, H. Teng, Structural features of nanotubes synthesized from $\mathrm{NaOH}$ treatment on $\mathrm{TiO}_{2}$ with different post-treatments, Chem. Mater. 18 (2006) 367-373. [30] W. Wang, J. Zhang, H. Huang, Z. Wu, Z. Zhang, Investigation on monolayer dispersion of benzoic acid supported on the surface of H-titanate nanotubes, Appl. Surf. Sci. 253 (2007) $5393-5399$.

[31] S. Zhang, W. Li, Z. Jin, J. Yang, J. Zhang, Z. Du, Z. Zhang, Study on ESR and interrelated properties of vacuum-dehydrated nanotubed titanic acid, J. Solid State Chem. 177 (2004) 1365-1371. 
[32] Q. Chen, G.H. Du, S. Zhang, L.-M. Peng, The structure of trititanate nanotubes, Acta Cryst. B58 (2002) 587-593.

[33] R. Ma, Y. Bando, T. Sasaki, Nanotubes of lepidocrocite titanates, Chem. Phys. Lett. 380 (2003) 577-582.

[34] Ch.-Ch. Tsai, J.-N. Nian, H. Teng, Mesoporous nanotube aggregates obtained from hydrothermally treating $\mathrm{TiO}_{2}$ with $\mathrm{NaOH}$, Appl. Surf. Sci. 253 (2006) 1898-1902.

[35] Ch.-K. Lee, S.-S. Liu, L.-Ch. Juang, Ch.-C. Wang, M.-D. Lyu, S.-H. Hung, Application of titanate nanotubes for dyes adsorptive removal from aqueous solution, J. Hazard. Mater. 148 (2007) 756-760.

[36] S. J. Rigby, A. H. R., Al-Obaidi, S.-K. Lee, D. McStay, P. K. J. Robertson, The application of Raman and anti-stokes Raman spectroscopy for in situ monitoring of structural changes in laser irradiated titanium dioxide materials, Appl. Surf. Sci. 252 (2006) 7948-7952. [37] L. Qian, Z.-L. Du, S.-Y. Yang, Z.-S. Jin, Raman study of titania nanotube by soft chemical process, J. Mol. Sci. 749 (2005)103-107.

[38] D. V. Bavykin, J. M. Friedrich, A. A. Lapkin, F. C. Walsh, Stability of aqueous suspensions of titanate natotubes, Chem. Mater. 18 (2006) 1124-1129.

[39] M. A. Cortés-Jácome, G. Ferrat-Torres, L. F. Flores Ortiz, C. Angeles-Chávez, E. LópezSalinas, J. Escobar, M. L. Mosqueira, J. A. Toledo-Antonio, In situ thermo-Raman study of titanium oxide nanotubes, Catal. Today 126 (2007) 248-255.

[40] V. P. Godbole, Y.-S. Kim, G.-S. Kim, M. A. Dar, H.-S. Shin, Synthesis of titanate nanotubes and its processing by different methods, Electrochim. Acta 52 (2006) 1781-1787. [41] Y. Ma, Y. Lin, X. Xiao, X. Zhou, X. Li, Sonication-hydrothermal combination technique for the synthesis of titanate nanotubes from commercially available precursors, Mater. Res. Bulletin 41 (2006) 237-243. 
[42] K. Hadjiivanov, FTIR study of $\mathrm{CO}$ and $\mathrm{NH}_{3}$ co-adsorption on $\mathrm{TiO}_{2}$ (rutile), Appl. Surf. Sci. 135 (1998) 331-338.

[43] G.-S. Guo, Ch.-N. He, Z.-H. Wang, F.-B. Gu, D.-M. Han, Synthesis of titania and titanate nanomaterials and their application in environmental analytical chemistry, Talanta 72 (2007) 1687-1692.

[44] A. J. Maira, J. M. Coronado, V. Augugliaro, K. L. Yeung, J. C. Conesa, J. Soria, Fourier Transform Infrared study of the performance of nanostructured $\mathrm{TiO}_{2}$ particles for the photocatalytic oxidation of gaseous toluene, J. Catal. 202 (2001) 413-420.

[45] W. Wang, J. Zhang, H. Huang, Z. Wu, Z. Zhang, Surface-modification and characterization of H-titanate nanotube, Colloid. Surface. A: Physicochem. Eng. Aspects 317 (2008) 270-276.

[46] A. Thorne, A. Kruth, D. Tunstall, J. T. S. Irvine, W. Zhou, Formation, structure, and stability of titanate nanotubes and their proton conductivity, J. Phys. Chem. 109 (2005) 54395444.

[47] International Union of Pure and Applied Chemistry, Reporting physisorption data for gas/solid systems with special reference to the determination of surface area and porosity (Recommendations 1984), Pure Appl. Chem. 57 (1985) 603-619.

[48] Ch.-Ch. Tsai, H. Teng, Regulation of the physical characteristics of titania nanotube aggregates synthesized from hydrothermal treatment, Chem. Mater. 16 (2004) 4352-4358. [49] N. Wang, H. Lin, J. Li, X. Yang, B. Chi, Ch. Lin, Effect of annealing temperature on phase transition and optical property of titanate nanotubes prepared by ion exchange approach, J. Alloy. Compd. 424 (2006) 311-314.

[50] N. Todorova, T. Giannakopoulou, G. Romanos, T. Vaimakis, Jiaguo Yu, C. Trapalis, Preparation of fluorine-doped $\mathrm{TiO}_{2}$ photocatalysts with controlled crystalline structure, Int. J. Photoenergy, Article ID 534038, 2008, 9 pages, doi:10.1155/2008/534038 
[51] J. Yu, H. Yu, Facile synthesis and characterization of novel nanocomposites of titanate nanotubes and rutile nanocrystals, Mater. Chem. Phys. 100 (2006) 507-512.

[52] M.A. Khan, D.H. Han, O.-B. Yang, Enhanced photoresponse towards visible light in ru doped titania nanotube, Appl. Surf. Sci. 255 (2009) 3687-3690.

[53] D. V. Bavykin, S. N. Gordeev, A. V. Moskalenko, A. A. Lapkin, F. C. Walsh, Apparent two-dimensional behavior of $\mathrm{TiO}_{2}$ nanotubes revealed by light absorption and luminescence, $\mathrm{J}$. Phys. Chem. B 109 (2005) 8565-8569.

[54] B. Kraeutler, A. J. Bard, Photoelectrosynthesis of ethane from acetate ion at an n-type $\mathrm{TiO}_{2}$ electrode. The photo-Kolbe reaction, J. Am. Chem. Soc. 99 (1977) 7729-7731.

[55] B. Kraeutler, A. J. Bard, Heterogenous photocatalytic synthesis of methane from acetic acid - new Kolbe reaction pathway, J. Am. Chem. Soc. 100 (1978) 2239-2240.

[56] B. Kraeutler, C. D. Jaeger, A. J. Bard, Direct observation of radical intermediates in the photo-Kolbe reaction -heterogenous photocatalytic radical formation by Electron Spin Resonance, J. Am. Chem. Soc. 100 (1978) 4903-4905.

[57] T. Sakata, T. Kawai, K. Hashimoto, Heterogenous photocatalytic reactions of organic acids in water. New reaction paths besides the photo-Kolbe reaction, J. Phys. Chem., 88 (1984) 2344-2350.

[58] G.R. Dey, K. K. Pushpa, Methane generated during photocatalytic redox reaction of alcohols on $\mathrm{TiO}_{2}$ suspension in aqueous solutions, Res. Chem. Intermed. 32 (2006) 725-736.

\section{FIGURE CAPTIONS}


Fig. 1. TEM images of (a-c) TNT130,24, (d-e) TNT130,48, (f-g) TNT140,24 and (h-j) TNT140,48.

Fig. 2. XRD patterns of TNTs prepared under different conditions and starting $\mathrm{TiO}_{2} \mathrm{P} 25 ; \mathrm{A}-$ anatase, $\mathrm{R}$ - rutile.

Fig. 3. Raman spectra of TNTs prepared under different conditions and starting $\mathrm{TiO}_{2} \mathrm{P} 25$.

Fig. 4. FTIR/DRS spectra of TNTs prepared under different conditions and starting $\mathrm{TiO}_{2} \mathrm{P} 25$.

Fig. 5. Thermogravimetric analysis of titanate nanotubes prepared under different conditions;

a) TG curves of different TNTs; b) TG and DTG curves of TNT130,24

Fig. 6. Nitrogen adsorption - desorption isotherms of TNTs prepared under different conditions.

Fig. 7. UV/Vis-DR spectra of TNT prepared under different conditions and starting $\mathrm{TiO}_{2} \mathrm{P} 25$.

Fig. 8. Changes of dye concentration in time during photocatalytic degradation of AR18 on P25 and TNT130,24.

Fig. 9. A comparison of the amount of products obtained after $5 \mathrm{~h}$ of photocatalytic reaction conducted in the presence of acetic acid with application of titanate nanotubes and P25.

\section{TABLE CAPTION}

Table 1. Selected properties of TNTs prepared under different conditions. 
Table 1. Selected properties of TNTs prepared under different conditions.

\begin{tabular}{llllll}
\hline Sample & $\begin{array}{l}\text { Synthesis } \\
\text { temperature }\left[{ }^{\circ} \mathrm{C}\right]\end{array}$ & $\begin{array}{l}\text { Synthesis } \\
\text { time }[\mathrm{h}]\end{array}$ & $\begin{array}{l}\text { BET surface } \\
\text { area }\left[\mathrm{m}^{2} / \mathrm{g}\right]\end{array}$ & $\begin{array}{l}\text { Pore volume } \\
{\left[\mathrm{cm}^{3} / \mathrm{g}\right]^{\mathrm{a})}}\end{array}$ & $\begin{array}{l}\text { Average pore } \\
\text { diameter }[\mathrm{nm}]^{*}\end{array}$ \\
\hline TNT130,24 & 130 & 24 & 386 & 1.31 & 13.6 \\
\hline TNT130,48 & 130 & 48 & 406 & 1.40 & 13.8 \\
\hline TNT140,24 & 140 & 24 & 450 & 1.54 & 13.7 \\
\hline TNT140,48 & 140 & 48 & 478 & 1.69 & 14.2 \\
\hline
\end{tabular}

a) Pore volume was determined by nitrogen adsorption at at $\mathrm{P} / \mathrm{P}_{\mathrm{o}}=0.995$ 

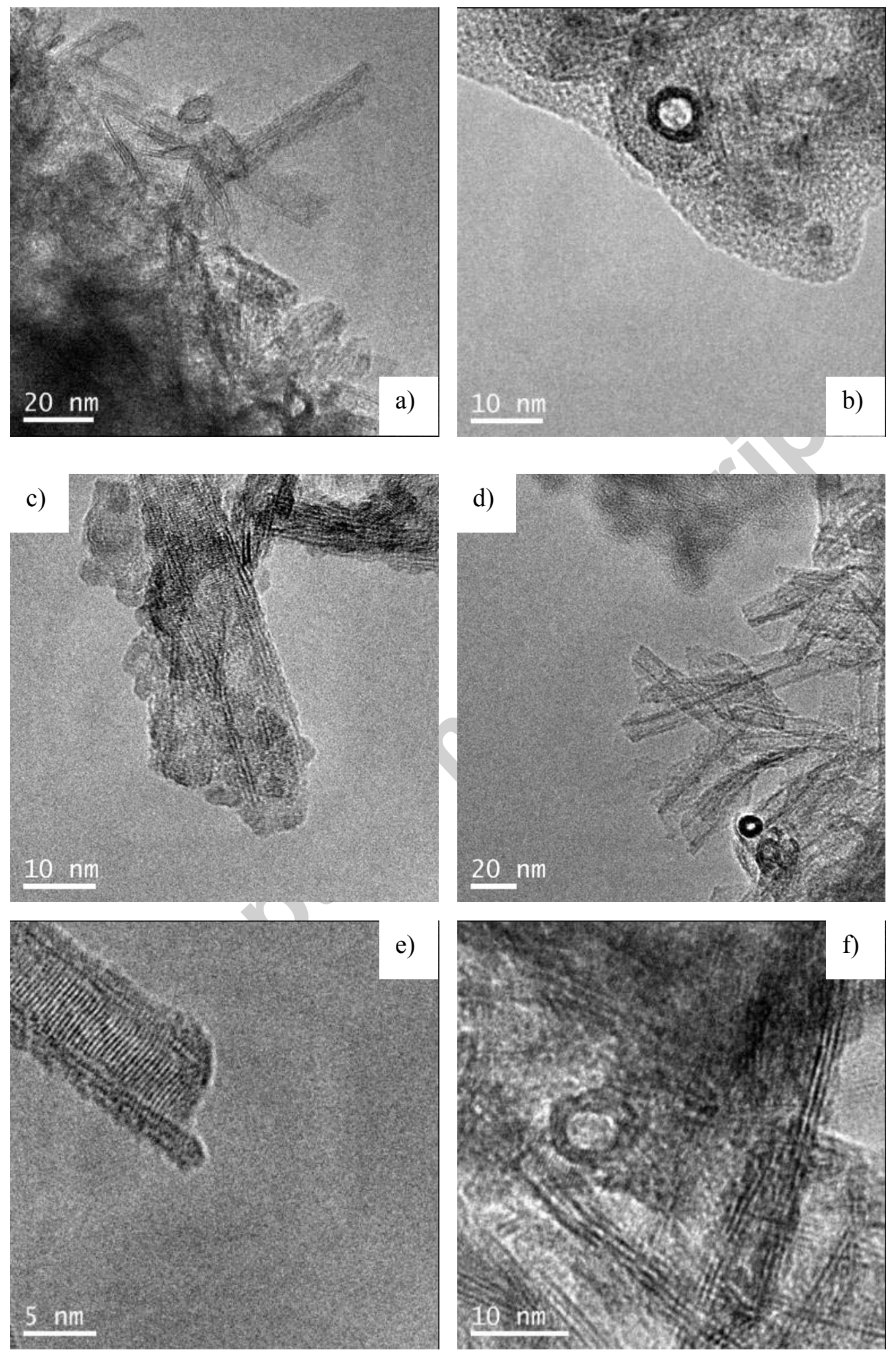

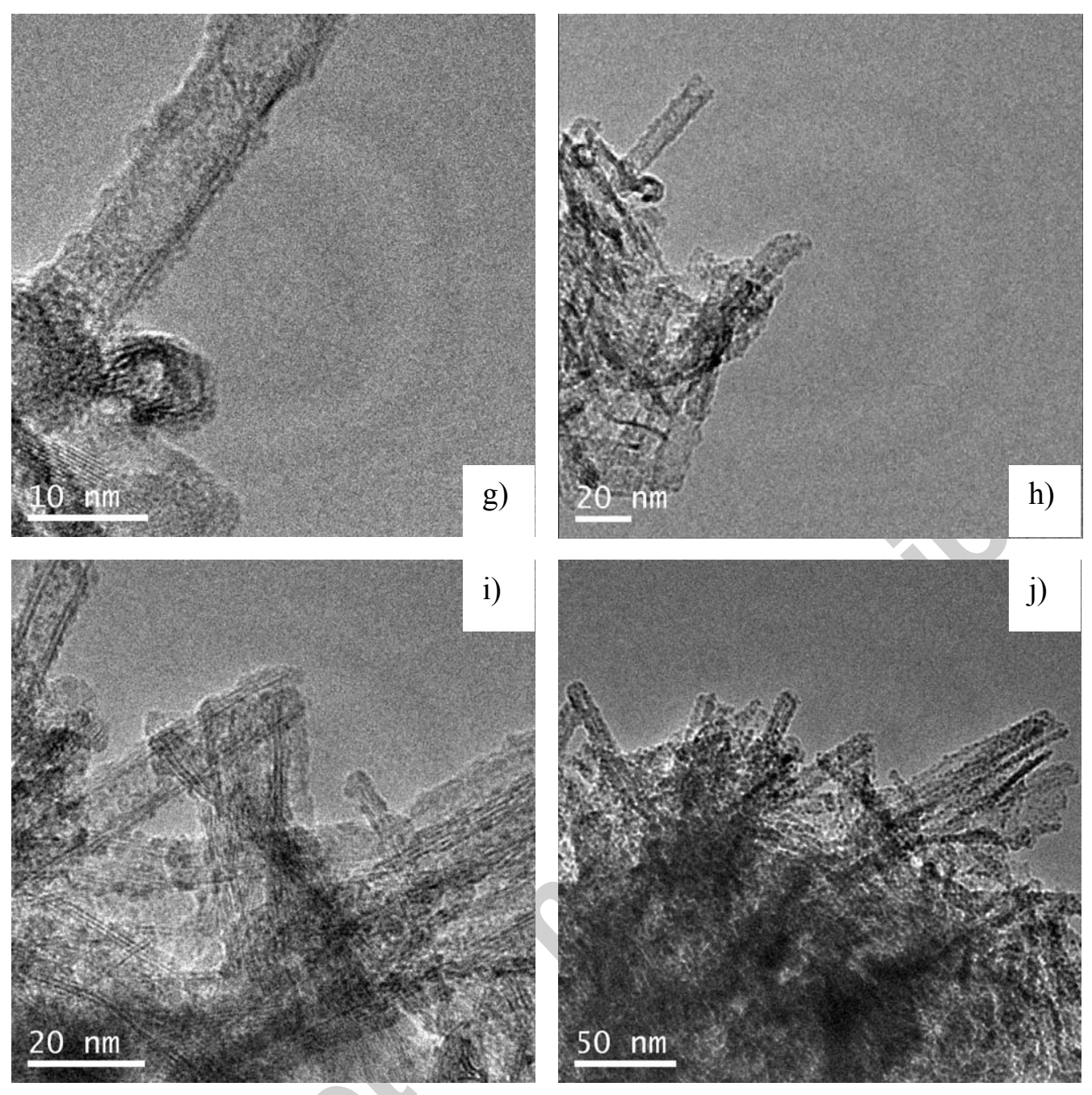

Fig. 1. TEM images of (a-c) TNT130,24, (d-e) TNT130,48, (f-g) TNT140,24 and (h-j) TNT140,48. 


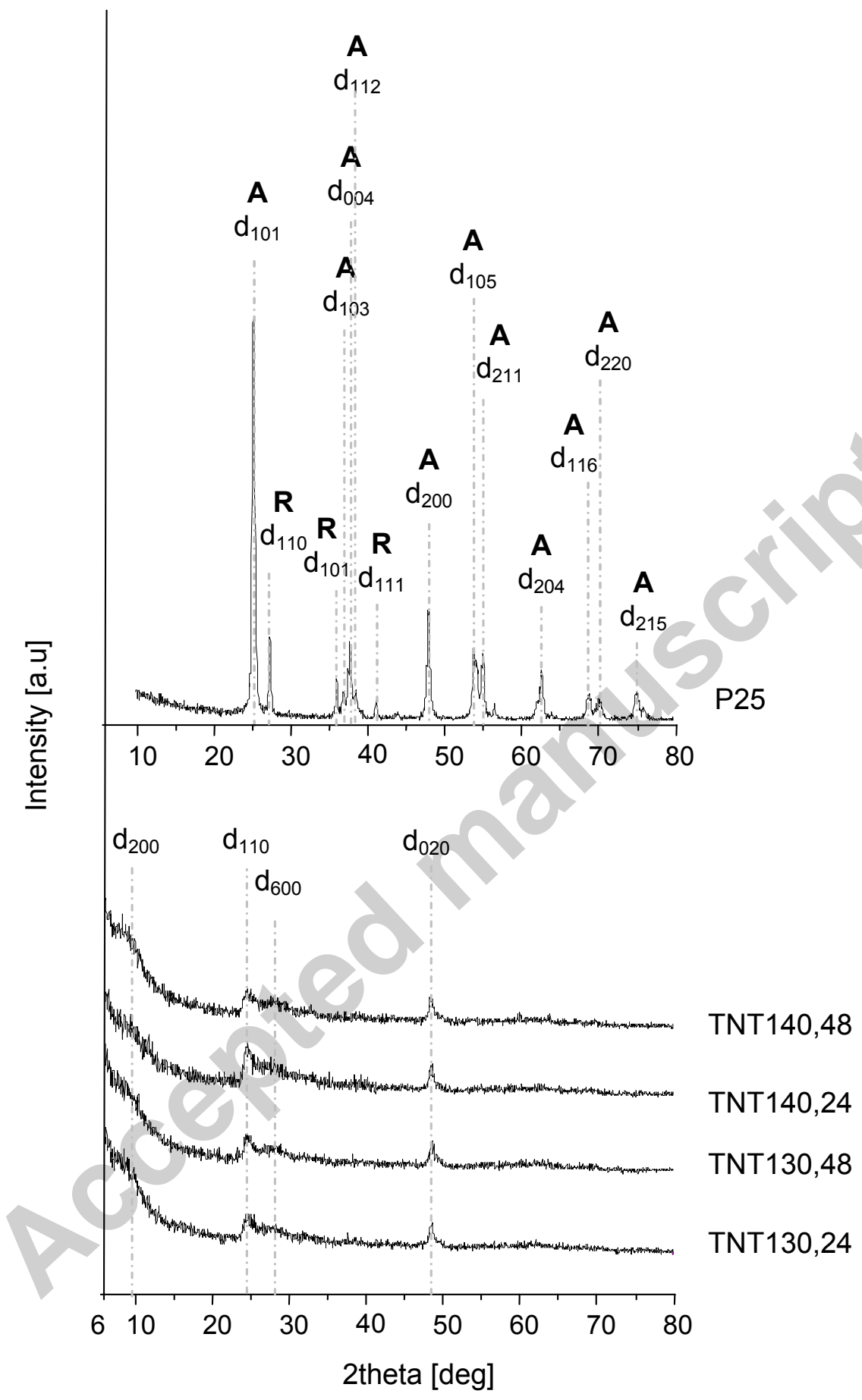

Fig. 2. XRD patterns of TNTs prepared under different conditions and starting $\mathrm{TiO}_{2} \mathrm{P} 25 ; \mathrm{A}-$ anatase, R- rutile. 


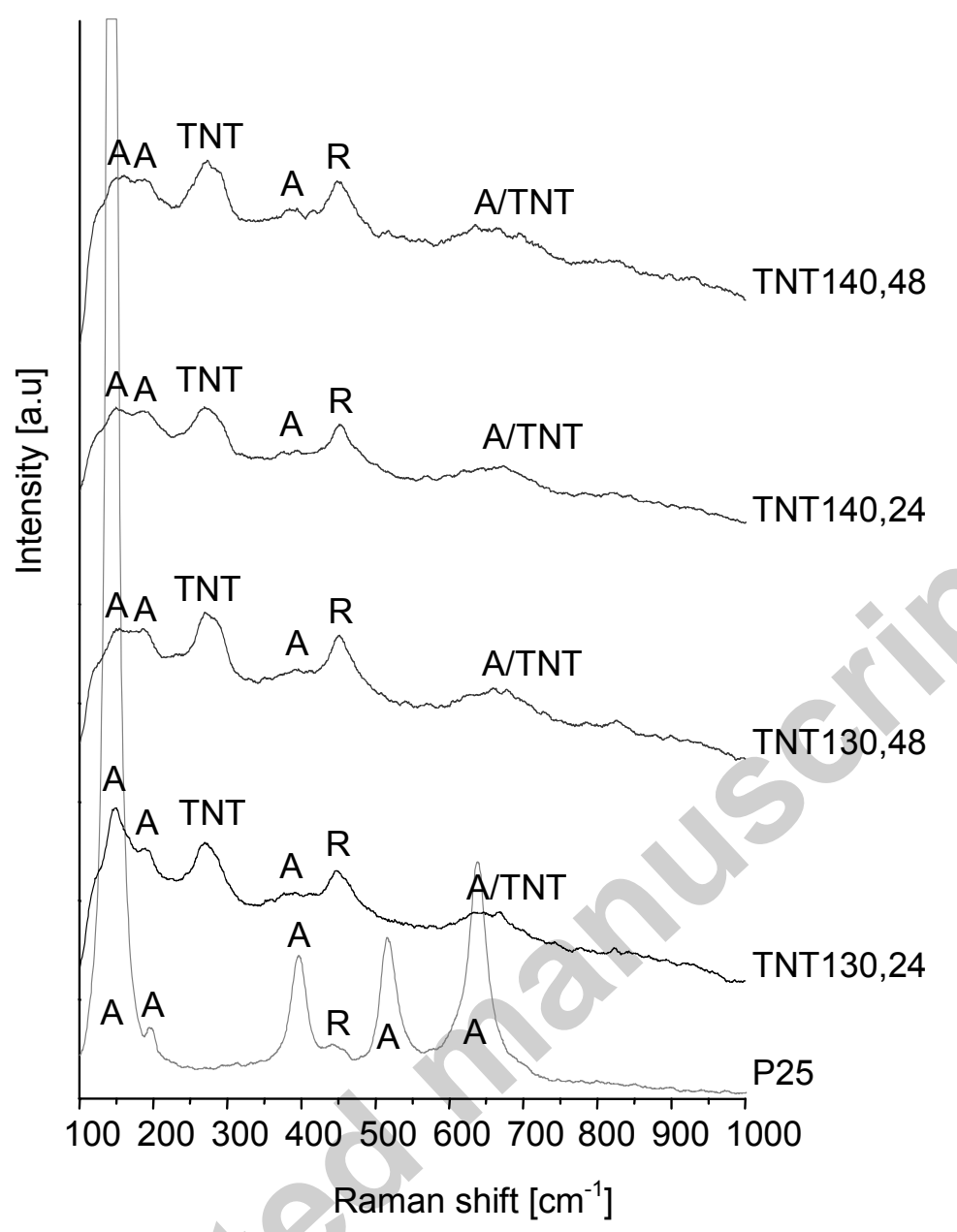

Fig. 3. Raman spectra of TNTs prepared under different conditions and starting $\mathrm{TiO}_{2} \mathrm{P} 25$. 


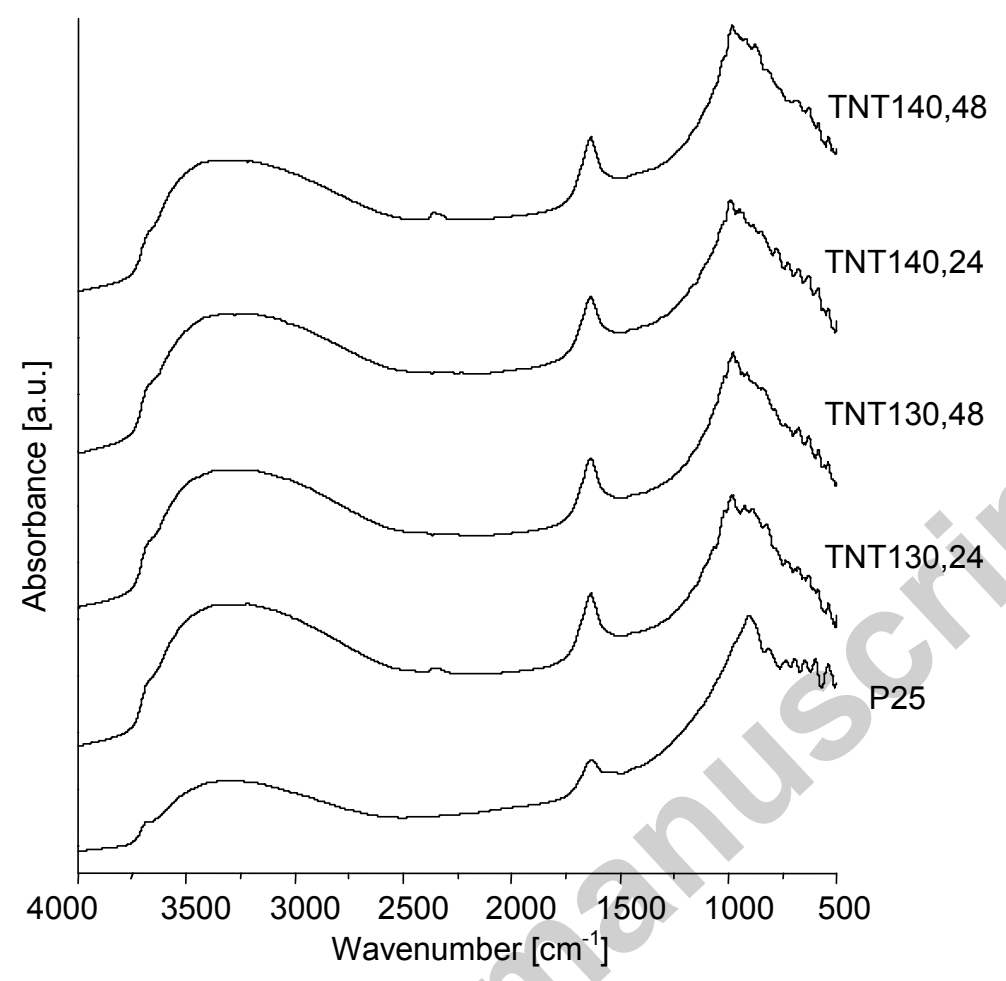

Fig. 4. FTIR/DRS spectra of TNTs prepared under different conditions and starting $\mathrm{TiO}_{2} \mathrm{P} 25$. 


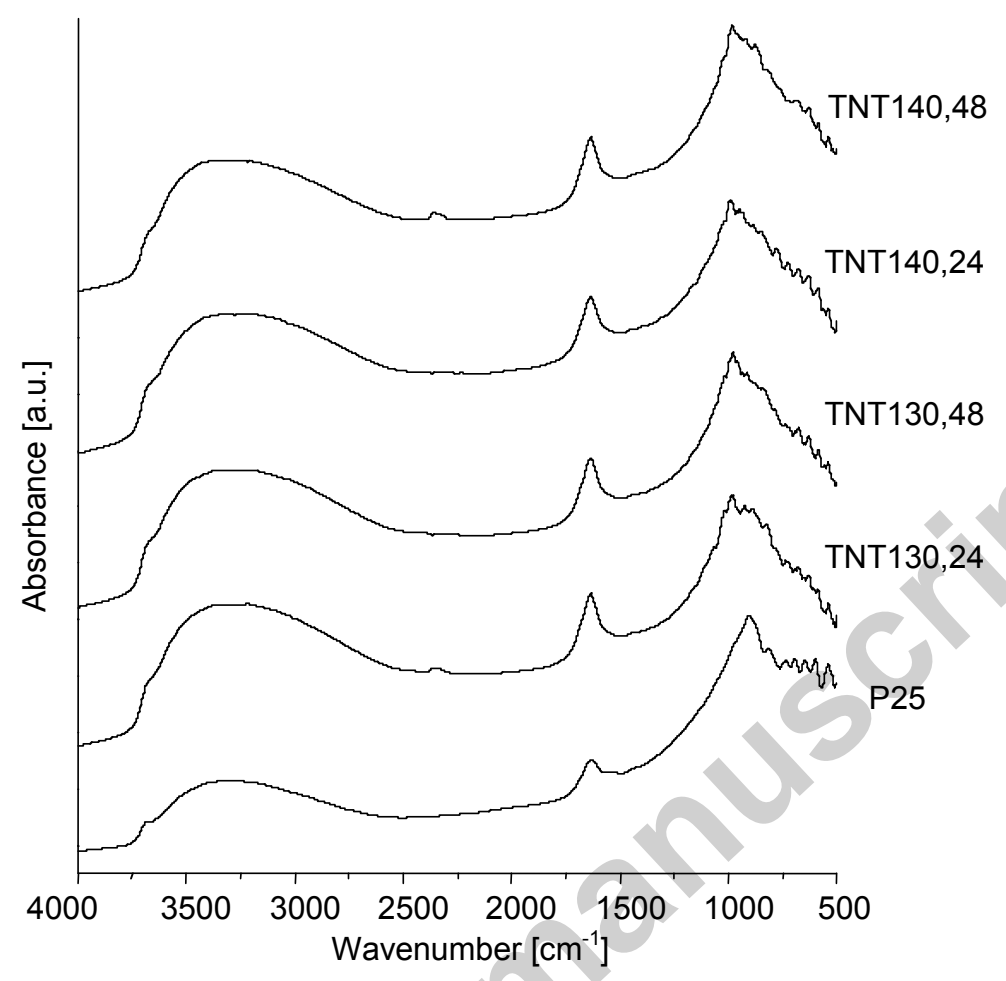

Fig. 4. FTIR/DRS spectra of TNTs prepared under different conditions and starting $\mathrm{TiO}_{2} \mathrm{P} 25$. 
a)

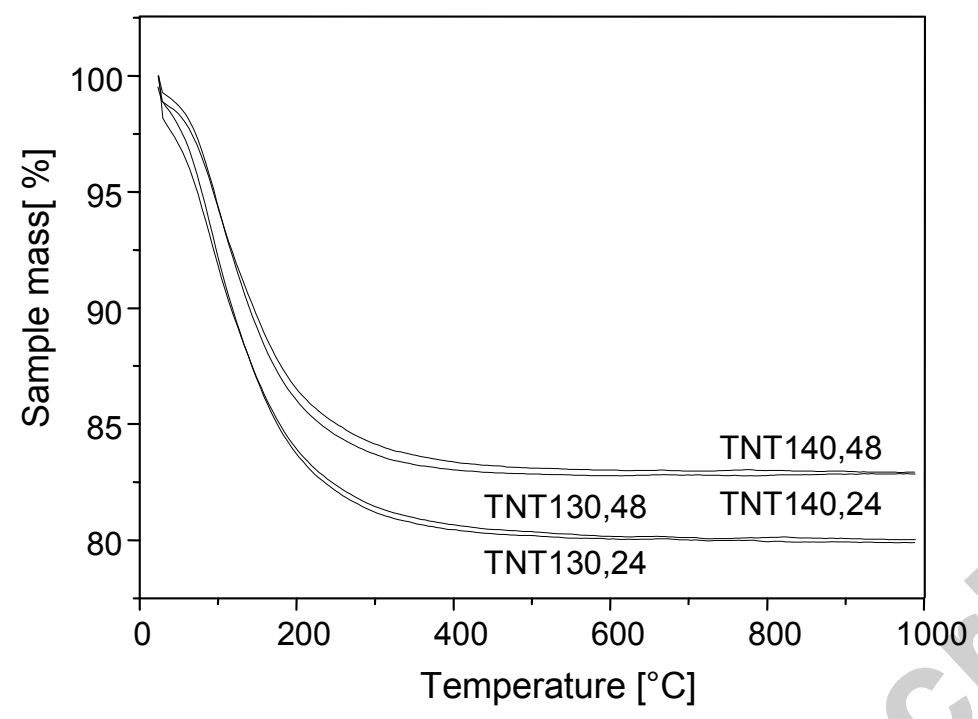

b)

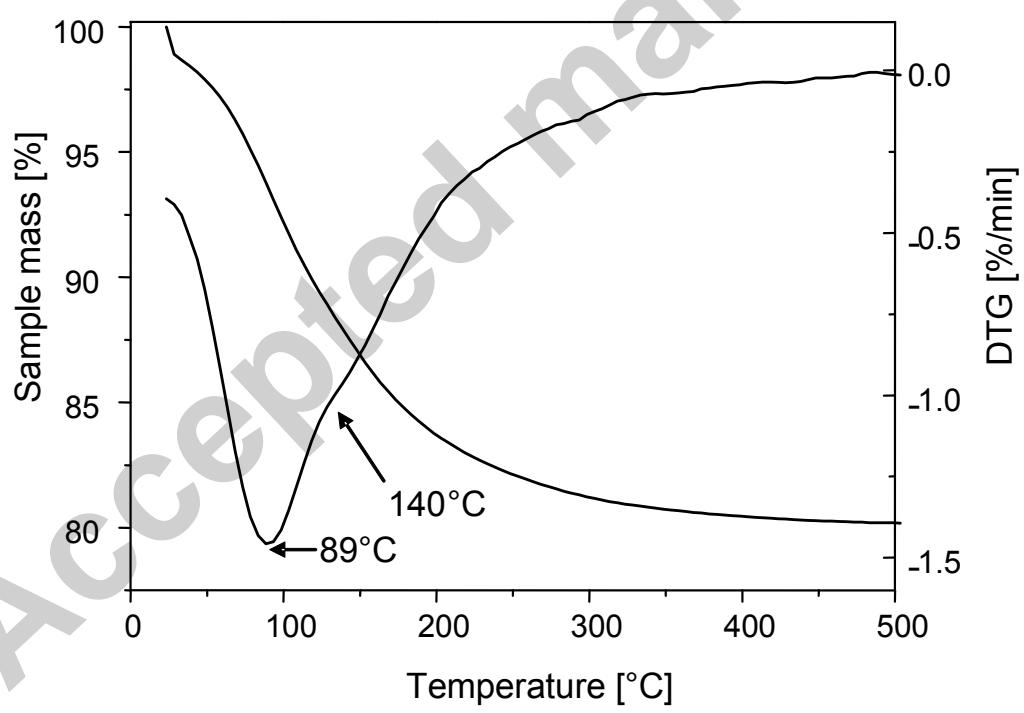

Fig. 5. Thermogravimetric analysis of titanate nanotubes prepared under different conditions; a) TG curves of different TNTs; b) TG and DTG curves of TNT130,24. 

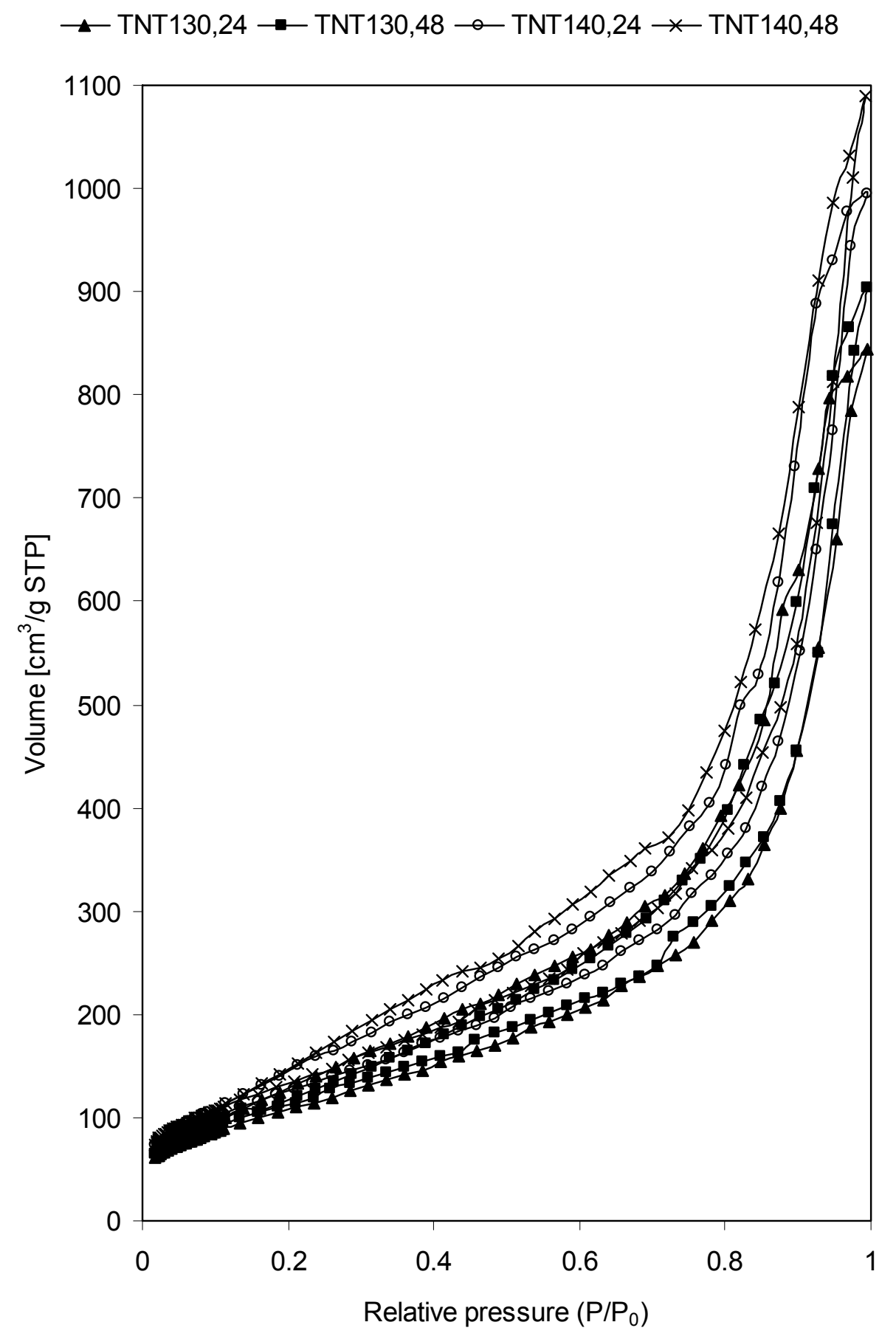

Fig. 6. Nitrogen adsorption - desorption isotherms of TNTs prepared under different conditions. 


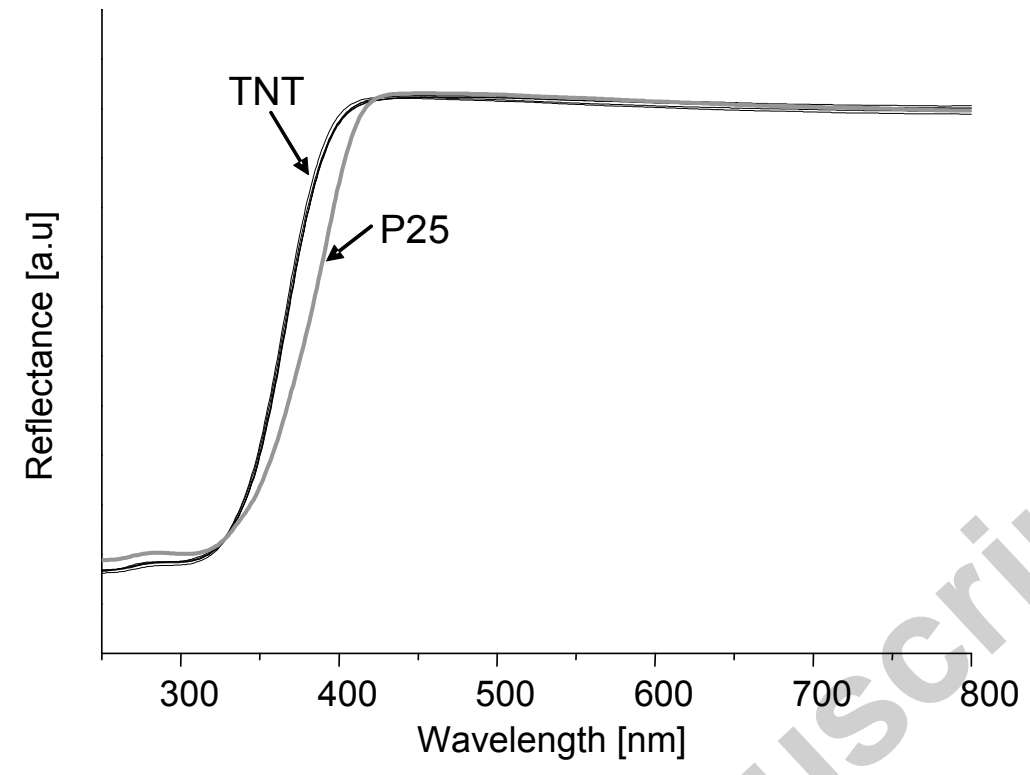

Fig. 7. UV/Vis-DR spectra of TNT prepared under different conditions and starting $\mathrm{TiO}_{2} \mathrm{P} 25$. 
$\multimap$ TNT130,24 $\rightarrow$ P25 $\triangle$ photolysis

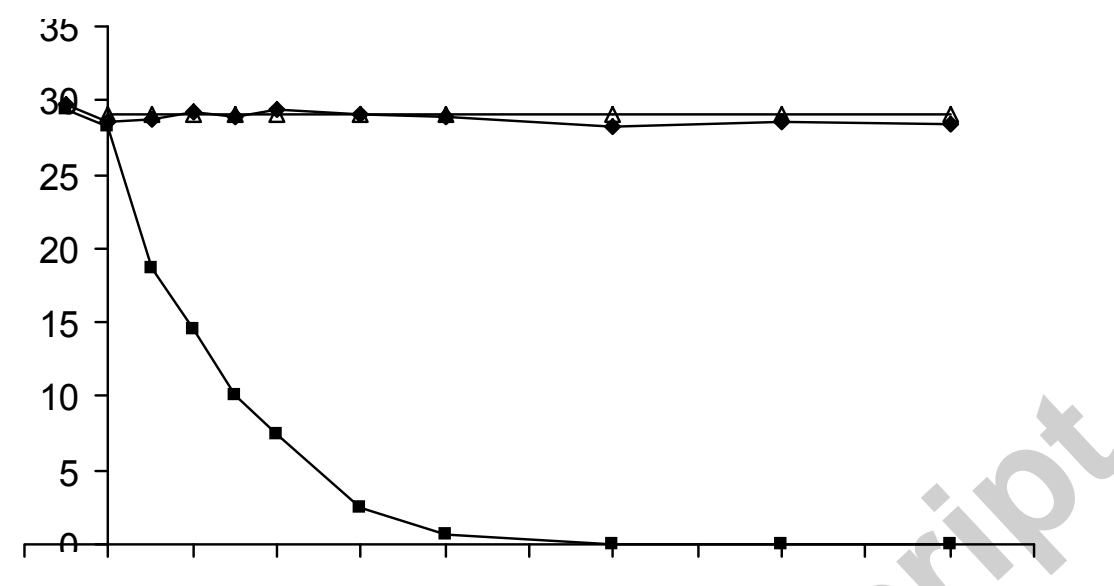

Fig. 8. Changes of dye concentration in time during photocatalytic degradation of AR18 on P25 and TNT130,24. 


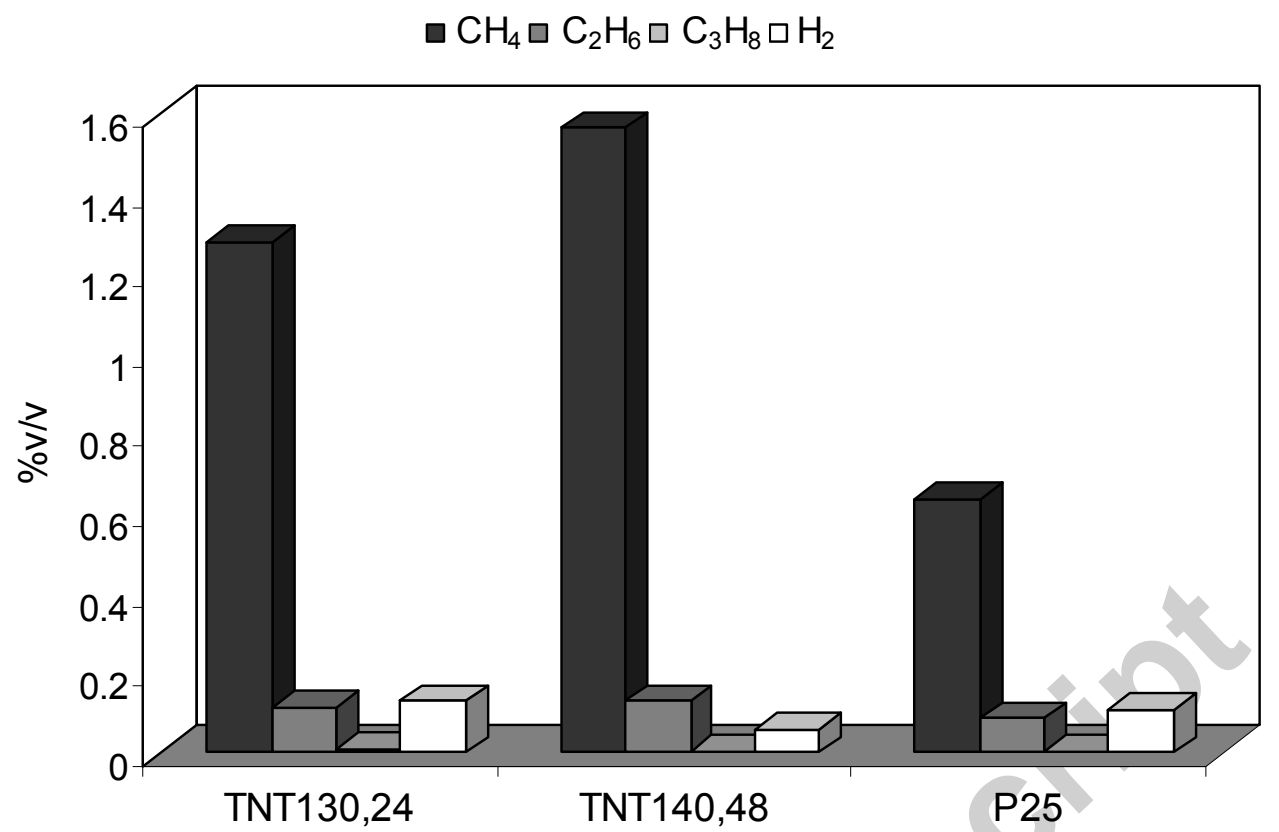

Fig. 9. A comparison of the amount of products obtained after $5 \mathrm{~h}$ of photocatalytic reaction conducted in the presence of acetic acid with application of titanate nanotubes and P25. 